\title{
Determinantes do "Milagre" Econômico Brasileiro (1968-1973): Uma Análise Empírica*
}

\author{
Fernando A. Veloso ${ }^{\dagger}$, André Villela ${ }^{\ddagger}$, Fabio Giambiagi ${ }^{\S}$
}

Sumário: 1. Introdução; 2. Uma Breve Descrição do "Milagre"; 3. Interpretações do "Milagre"

4. Metodologia Econométrica e Descrição das Variáveis; 5. Resultados; 6. Conclusões;

Palavras-chave: Milagre Econômico Brasileiro; Painel Dinâmico; Reformas Institucionais; Política Econômica.

Códigos JEL: C33; O40; 054.

O objetivo deste estudo é quantificar, através de uma metodologia de regressão de crescimento com dados de painel, a importância de possíveis determinantes do "milagre" econômico brasileiro de 1968-1973. Em particular, verificamos em que medida o "milagre" decorreu da situação externa favorável, do desempenho de variáveis de política econômica no período 1968-1973 e das reformas institucionais do Programa de Ação Econômica do Governo (PAEG) do Governo Castello Branco (1964-1967). Os resultados mostram que tanto o ambiente externo como as variáveis de política econômica explicam uma parcela relativamente pequena da aceleração do crescimento observada entre 1962-1967 e 1968-1973. Isso decorre do fato de que o modelo de crescimento estimado com base em painéis de seis anos superestima fortemente o crescimento econômico brasileiro no período anterior ao "milagre" e subestima o crescimento no período do "milagre". Os resultados mostram, no entanto, que o modelo estimado para painéis de dez anos prevê para o período 1964-1973 uma taxa de crescimento bastante próxima da taxa de crescimento efetivamente verificada. Em conjunto, nossos resultados indicam que o episódio de aceleração do crescimento associado ao "milagre" decorreu em grande medida do efeito defasado das reformas associadas ao PAEG.

\footnotetext{
*Os autores agradecem os comentários e sugestões de Antônio Delfim Netto, Edmar Bacha, Fernando Nascimento de Oliveira, José Guilherme de Lara Resende, Marcelo Mello, Régis Bonelli, Samuel Pessôa e participantes em seminários no Banco Central-RJ, Fundação João Pinheiro-MG, Universidade de Brasília, FGV-RJ e IPEA-RJ. Fernando Veloso agradece o apoio financeiro do CNPq. Erros remanescentes são de total responsabilidade dos autores.

${ }^{\dagger}$ Ibmec-RJ. E-mail: fveloso@ibmecrj . br

${ }^{\ddagger}$ EPGE/FGV e UCAM. E-mail: Andre.Villela@fgv.br

$\S$ BNDES. E-mail: fgiambia@bndes.gov.br
} 
The goal of this paper is to quantify, using a growth regression methodology with panel data, the importance of possible determinants of the Brazilian economic "miracle" of 1968-1973. In particular, we verify to what extent the "miracle" was due to the favourable external environment, to the economic policy variables in the period 1968-1973 and to the institutional reforms associated with the Programa de Ação Econômica do Governo (PAEG) implemented during the Castello Branco presidential term (1964-1967). The results show that both the external environment and the economic policy variables explain a relatively small fraction of the growth acceleration between 1962-1967 and 1968-1973. This is due to the fact that the growth model estimated using a six-year panel overestimates considerably the Brazilian economic growth in the period that preceded the "miracle" and underestimates the growth rate for the "miracle" period. The results show, however, that the model estimated using a ten-year panel predicts a growth rate for the period 1964-1973 that is very close to the one actually observed. Taken together, our results indicate that the growth acceleration episode associated with the "miracle" was due to a large extent to the delayed effect of the reforms associated with the PAEG.

\section{INTRODUÇÃO}

O período 1968-1973 é conhecido como "milagre" econômico brasileiro, em função das extraordinárias taxas de crescimento do Produto Interno Bruto (PIB) então verificadas, de $11,1 \%$ ao ano (a.a.). Uma característica notável do "milagre" é que o rápido crescimento veio acompanhado de inflação declinante e relativamente baixa para os padrões brasileiros, além de superávits no balanço de pagamentos.

Embora esse período tenha sido amplamente estudado, não existe um consenso em relação aos determinantes últimos do "milagre". As interpretações encontradas na literatura podem ser agrupadas em três grandes linhas. A primeira linha de interpretação enfatiza a importância da política econômica do período, com destaque para as políticas monetária e creditícia expansionistas e os incentivos às exportações. Uma segunda vertente atribui grande parte do "milagre" ao ambiente externo favorável, devido à grande expansão da economia internacional, melhoria dos termos de troca e crédito externo farto e barato. Já uma terceira linha de interpretação credita grande parte do "milagre" às reformas institucionais do Programa de Ação Econômica do Governo (PAEG) do Governo Castello Branco (19641967), em particular às reformas fiscais/tributárias e financeira, que teriam criado as condições para a aceleração subseqüente do crescimento. ${ }^{1}$

O objetivo desse artigo é quantificar, através de uma metodologia de regressões de crescimento com dados de painel, a importância de possíveis determinantes do "milagre" brasileiro. Em particular, verificamos em que medida o "milagre" decorreu da situação externa favorável e do desempenho de variáveis de política econômica associadas à estabilidade macroeconômica, política fiscal, nível de desenvolvimento do sistema financeiro e grau de abertura ao exterior. Também investigamos até que ponto o crescimento econômico observado no período 1968-1973 decorreu das reformas implementadas a partir de 1964 .

\footnotetext{
${ }^{1}$ Essas explicações não são necessariamente excludentes. Por exemplo, Simonsen e Campos (1974) argumentam que tanto as reformas institucionais do período 1964-1967 quanto a política econômica do período 1968-1973 foram os principais determinantes do "milagre". Hermann (2005) enfatiza a situação externa favorável e a política econômica do período 1968-1973. Mais adiante, a literatura sobre as interpretações do "milagre" será discutida em detalhe.
} 
Neste artigo, estimaremos regressões de painel baseadas em uma versão ampliada do modelo neoclássico de crescimento. Utilizaremos inicialmente painéis de seis anos para uma amostra de 62 países, durante o período entre 1962 e 1997, onde um dos subperíodos corresponde aos anos do "milagre".

Embora o painel seja estimado para o período 1962-1997, o objetivo da análise é quantificar o crescimento previsto pelo modelo para o período do "milagre" econômico brasileiro de 1968-1973, e avaliar até que ponto este modelo consegue explicar a aceleração de crescimento de 1968-1973 em relação ao período anterior (1962-1967).

A metodologia de quantificação dos determinantes do crescimento utilizada nesse artigo baseia-se em Easterly et alii (1997), que avaliaram o efeito das reformas econômicas no crescimento econômico da América Latina entre 1991 e 1993. Essa metodologia tem sido recentemente empregada em diversos estudos que procuram quantificar os determinantes do crescimento na América Latina, como, por exemplo, De Gregorio e Lee (1999), Fernández-Arias e Montiel (2001) e Loayza et alii (2005).

Uma contribuição deste artigo é o fato de combinar a literatura de regressões de crescimento com dados de painel com o estudo de um episódio de aceleração de crescimento, na medida em que a escolha dos períodos no painel foi feita de modo a cobrir o período de duração do "milagre" econômico brasileiro.

Os resultados mostram que tanto o ambiente externo como as variáveis de política econômica explicam uma parcela relativamente pequena da aceleração do crescimento brasileiro observada entre 1962-1967 e 1968-1973. Esses resultados são robustos ao uso de diferentes metodologias econométricas, como o estimador de efeito fixo, o estimador GMM em diferenças de Arellano e Bond (1991) e o estimador GMM de sistema de Blundell e Bond (1998). Os resultados também são robustos à inclusão nas regressões da razão investimento/PIB e da variável de abertura de Sachs e Warner (1995).

Em princípio, essa evidência parece corroborar os resultados de estudos recentes sobre episódios de aceleração do crescimento, como Hausmann et alii (2005) e Rodrik e Subramanian (2004). Em um estudo sobre mais de 80 episódios de aceleração do crescimento desde a década de 1950, Hausmann et alii (2005) apresentam evidências de que acelerações de crescimento são em larga medida imprevisíveis. Em particular, a maioria dos episódios de aceleração de crescimento não está relacionada aos determinantes comumente postulados em regressões de crescimento, e reformas econômicas em geral não produzem acelerações de crescimento. Rodrik e Subramanian (2004) confirmam esse resultado em um estudo de um episódio de aceleração do crescimento na Índia durante a década de 1980.

No entanto, um estudo mais aprofundado do período 1968-1973 no Brasil mostra que essa interpretação não é apropriada no caso do "milagre" brasileiro. A primeira evidência nesse sentido é o fato de que o modelo de crescimento estimado com base em painéis de seis anos superestima fortemente o crescimento econômico brasileiro no período anterior ao "milagre" e subestima o crescimento no período em que ele ocorreu. Isso sugere a possibilidade de que, pelo menos em parte, a aceleração de crescimento associada ao "milagre" tenha decorrido do efeito defasado das reformas do PAEG.

De fato, Simonsen e Campos (1974) atribuem parte do "milagre" às reformas econômicas implementadas no Governo Castello Branco. Nesse sentido, os principais formuladores do PAEG argumentam que o período 1964-1973 deve ser visto de forma unificada. A interpretação dos autores é de que, a partir de 1964, o modelo econômico brasileiro teria mudado, no sentido de transformar a economia brasileira em uma economia de mercado aberta ao exterior. Segundo os autores, o período 1964-1967 teria sido um período caracterizado por um "esforço de restauração", diante da situação de descontrole inflacionário, déficits crônicos no balanço de pagamentos e colapso do investimento herdados do governo anterior, o que implicaria um sacrifício temporário das taxas de crescimento. Em função do ajuste macroeconômico e das reformas institucionais associadas ao PAEG, teriam sido criadas as condições que tornariam possível a aceleração do crescimento no período 1968-1973.

Para testar essa conjectura, estendemos nossa análise para painéis de dez anos, incluindo o período 1964-1973 entre seus subperíodos. Os resultados mostram que o modelo de regressões de crescimento com dados de painel prevê uma taxa de crescimento para o Brasil no período 1964-1973 bastante próxima da taxa de crescimento efetivamente verificada no período. 
A combinação dos resultados dos painéis de crescimento de seis e dez anos conduz, portanto, a uma interpretação do "milagre" brasileiro bastante distinta da que decorre dos estudos de aceleração de crescimento de Hausmann et alii (2005) e Rodrik e Subramanian (2004). Em conjunto, nossos resultados indicam que o episódio de aceleração do crescimento associado ao "milagre" decorreu em grande medida do efeito defasado das reformas associadas ao PAEG.

O artigo está organizado em cinco seções, além desta introdução. Na seção 2, é apresentada uma análise descritiva do "milagre". A seção 3 discute as diversas interpretações do "milagre" encontradas na literatura. Na seção 4 são apresentadas a metodologia econométrica e uma descrição das variáveis utilizadas nas regressões. Na seção 5 são apresentados os principais resultados para painéis de seis e dez anos. As principais conclusões do artigo estão reunidas na seção 6.

\section{UMA BREVE DESCRIÇÃO DO “MILAGRE”}

Durante o período 1968-1973, o PIB brasileiro cresceu a uma taxa de cerca de $11,1 \%$ a.a., enquanto no período 1964-1967 o crescimento havia sido de 4,2\% a.a.. ${ }^{2}$ Como mostra a Tabela 1, uma característica notável do "milagre" é que, simultaneamente a taxas muito elevadas de crescimento econômico, o período 1968-1973 caracterizou-se por taxas de inflação declinantes e relativamente baixas para os padrões brasileiros e por superávits no balanço de pagamentos.

Tabela 1 - Brasil: Indicadores Macroeconômicos Selecionados - 1968-1973

\begin{tabular}{|l|c|c|c|c|c|c|}
\hline \multicolumn{1}{|c|}{ Indicadores Selecionados } & 1968 & 1969 & 1970 & 1971 & 1972 & 1973 \\
\hline Taxa de crescimento do PIB (\%) & 9,8 & 9,5 & 10,4 & 11,3 & 11,9 & 14,0 \\
Inflação (IGP,\%) & 25,5 & 19,3 & 19,3 & 19,5 & 15,7 & 15,6 \\
Taxa de crescimento das exportações em US\$ (\%) & 13,7 & 22,9 & 18,5 & 6,0 & 37,4 & 55,3 \\
Taxa de crescimento das importações em US\$ (\%) & 28,7 & 7,4 & 25,8 & 29,5 & 30,3 & 46,3 \\
Saldo da Balança Comercial (em US\$ milhões) & 26 & 318 & 232 & -344 & -241 & 7 \\
Saldo em Conta Corrente (em US\$ milhões) & -582 & -364 & -839 & -1.630 & -1.688 & -2.085 \\
Dívida Externa Líquida/Exportação de Bens & 2,0 & 1,7 & 1,8 & 2,3 & 1,8 & 1,4 \\
Saldo do Balanço de Pagamentos (em US\$ milhões) & 97 & 531 & 534 & 537 & 2.538 & 2.380 \\
\hline
\end{tabular}

Fonte: Apêndice Estatístico em Giambiagi et alii (2005).

Como se pode observar na Tabela 1, enquanto a taxa de crescimento do PIB acelerou-se ao longo do tempo, elevando-se de 9,8\% a.a. em 1968 para 14\% a.a em 1973, a inflação, medida pelo Índice Geral de Preço (IGP), declinou de $25,5 \%$ para $15,6 \%$ durante o período.

Além disso, embora o saldo de transações correntes tenha sido deficitário no período, o balanço de pagamentos foi superavitário em todos os anos e crescente ao longo do período, em função da entrada líquida de capitais de empréstimo e investimentos diretos. Também deve ser destacado que, em função do crescimento extraordinário das exportações, a relação dívida externa líquida/exportações declinou de 2,0 para 1,4 entre 1968 e 1973.

A Tabela 2 contrasta vários indicadores econômicos do período 1968-1973 com o período 1964-1967. Ela confirma que o período 1968-1973 foi extraordinário não somente no que diz respeito às taxas de crescimento econômico, mas também em relação ao comportamento da inflação e das contas externas.

Como mostra a Tabela 2, enquanto a taxa média de crescimento do PIB elevou-se de $4,2 \%$ a.a no período 1964-1967 para 11,1\% a.a em 1968-1973, a taxa de inflação declinou de 45,4\% para 19,1\%. Também se verificou uma forte aceleração na taxa de crescimento das exportações e importações em 1968-1973, saltando de $4,1 \%$ e $2,7 \%$ a.a. para $24,6 \%$ e $27,5 \%$ a.a., respectivamente, entre os dois períodos.

\footnotetext{
${ }^{2}$ Hausmann et alii (2005) incluem a experiência brasileira de crescimento a partir de 1967 em seu estudo sobre os determinantes de episódios de aceleração extraordinária do crescimento.
} 
Tabela 2 - Brasil: Comparação de Indicadores Macroeconômicos: 1964-1967 e 1968-1973

\begin{tabular}{|l|c|c|}
\hline \multicolumn{1}{|c|}{ Indicadores Selecionados } & $\begin{array}{c}\text { Média } \\
1964-1967\end{array}$ & $\begin{array}{c}\text { Média } \\
1968-1973\end{array}$ \\
\hline Taxa de crescimento do PIB (\% a.a.) & 4,2 & 11,1 \\
Inflação (IGP\% a.a.) & 45,5 & 19,1 \\
Taxa de crescimento das exportações em US\$ (\% a.a.) & 4,1 & 24,6 \\
Taxa de crescimento das importações em US\$ (\% a.a.) & 2,7 & 27,5 \\
Saldo da Balança Comercial (em US\$ milhões) & 412 & 0 \\
Saldo em Conta Corrente (em US\$ milhões) & 15 & -1.198 \\
Dívida Externa Líquida/Exportação de Bens & 2,0 & 1,8 \\
Saldo do Balanço de Pagamentos (em US\$ milhões) & $-13,8$ & $1.102,8$ \\
\hline
\end{tabular}

Embora o saldo de transações correntes tenha se deteriorado em cerca de US\$ 1,2 bilhão ao ano em 1968-1973, o saldo do balanço de pagamentos, que era deficitário em US\$ 13,8 milhões em 1964-1967, tornou-se superavitário em US\$ 1,1 bilhão, em média anual, no período 1968-1973.

Alguns estudos recentes têm revelado outra dimensão importante do "milagre", que não tinha sido enfatizada anteriormente. Em particular, Gomes et alii (2003) mostram, utilizando uma metodologia de contabilidade do crescimento, que o crescimento da produtividade total dos fatores (PTF) foi o principal determinante do crescimento econômico brasileiro entre 1967 e 1976. Os autores também documentam uma queda da relação capital-produto no período.

Um estudo de Bacha e Bonelli (2004) também forneceu evidências de que o período 1968-1973 se distingue dos demais no que diz respeito ao comportamento da produtividade. Os autores mostram que, entre 1946 e 2002, houve uma forte tendência de declínio da relação entre o produto e uma medida do estoque de capital ajustado pelo seu grau de utilização. No entanto, entre 1968 e 1973, houve uma elevação da relação produto-capital em uso, o que é consistente com a queda da relação capital-produto encontrada em Gomes et alii (2003) para o período 1967-1976.

Portanto, a literatura brasileira recente de crescimento econômico fornece sólidas evidências de que o "milagre" brasileiro foi um "milagre" de produtividade.

\section{INTERPRETAÇÕES DO “MILAGRE"}

As interpretações sobre os fatores determinantes do "milagre" encontradas na literatura podem ser divididas em três grandes grupos, não necessariamente excludentes, e que enfatizam: ${ }^{3}$

a) A política econômica do período 1968-1973, com destaque para as políticas monetária e creditícia expansionistas e os incentivos às exportações;

b) O ambiente externo favorável, devido à grande expansão da economia internacional, melhoria dos termos de troca e crédito externo farto e barato;

c) As reformas institucionais do PAEG, em particular as reformas fiscais/tributárias e financeira, que teriam criado as condições para a aceleração subseqüente do crescimento.

No restante desta seção cada um destes determinantes é discutido em maior detalhe.

\footnotetext{
${ }^{3}$ As explicações recentes do "milagre" baseadas no crescimento da PTF estão indiretamente vinculadas a pelo menos uma das explicações acima. Gomes et alii (2003), por exemplo, conjecturam que as reformas do PAEG seriam em parte responsáveis pelo grande aumento das taxas de crescimento da PTF e do produto por trabalhador em 1968-1973.
} 


\subsection{A Política Macroeconômica do Período 1968-1973}

No período 1964-1967, as taxas de crescimento anuais médias em termos reais do M1 e do crédito foram de $4,8 \%$ e $4,9 \%$, respectivamente. No período $1968-1973$, essas taxas elevaram-se para $13,9 \%$ e $17,4 \%$, respectivamente. Outro dado importante é que, enquanto no período 1964-1967 o crescimento médio anual real do crédito ao setor privado foi de $7,4 \%$, essa taxa elevou-se para $25,4 \%$ no período 1968-1973, ao passoa que a taxa de crescimento anual real do crédito ao setor público, de 1,1\% em 19641967, foi de -16,2\% em 1968-1973 (Hermann, 2005). Em resumo, o período 1968-1973 foi caracterizado por uma grande expansão real da moeda e do crédito, e esse último foi canalizado para o setor privado.

No que se refere às exportações, o estímulo governamental assumiu diversas formas, entre as quais a introdução do sistema de minidesvalorizações cambiais (crawling peg) a partir de 1968, e a criação do Programa Befiex em 1972, permitindo às empresas com planos de exportação contar com uma série de facilidades de importação, sujeitas ao desempenho exportador futuro.

Tomadas em conjunto e tendo em vista o excelente ambiente externo da época, tais medidas ajudam a explicar o excepcional desempenho exportador observado durante o "milagre": taxas de crescimento anuais médias de $24,6 \%$ do valor (em US\$) das exportações, e de $39,5 \%$ no caso de manufaturados. Em 1973, a vulnerabilidade externa do país, medida pela relação dívida externa líquida/exportações, caiu para o nível de 1,4, que foi o valor mais baixo desse indicador no período 1956-2004 no Brasil. ${ }^{4}$

\subsection{Ambiente Externo Favorável}

O ambiente internacional no período 1968-1973 foi particularmente benigno, tendo sido verificada uma conjunção favorável das seguintes variáveis externas: termos de troca favoráveis, forte expansão do volume de comércio internacional, baixas taxas de juros e farta disponibilidade de crédito no mercado externo.

O aumento da liquidez internacional resultante da criação do mercado de eurodólares no final da década de 60 permitiu a ampliação das possibilidades de endividamento dos países tomadores, entre os quais o Brasil. Tal movimento beneficiou o Brasil não apenas pelo aumento do volume de crédito externo de que passou a dispor, mas também pelo baixo custo desses empréstimos, envolvendo taxas reais de juros da ordem de $2 \%$ a.a.

Além disso, o fluxo de investimento externo direto (IED) para o Brasil dobrou de patamar no início dos anos 70, tendo ultrapassado US\$ 1,1 bilhão em 1973. Juntos, o crescente endividamento externo e os fluxos de IED garantiram a dimensão externa do "milagre", sob a forma de um balanço de pagamentos superavitário em meio a taxas de crescimento econômico de dois dígitos.

Nesse contexto, o Brasil pôde, durante vários anos, usufruir os benefícios da conjuntura externa sem enfrentar os problemas de balanço de pagamentos normalmente associados às fases de crescimento acelerado. Isso ocorreu não só porque a disponibilidade de crédito externo assegurava o financiamento do déficit em transações correntes, mas, também, devido à expansão do quantum exportado e à melhoria dos termos de troca, que permitiram a ampliação da capacidade de importar do país.

Paralelamente, devido ao forte ritmo de expansão do comércio internacional (17,8\% a.a., em dólares correntes, entre 1968 e 1973), os preços das commodities no mercado mundial também se elevaram consideravelmente. No período 1970-1973, o preço médio dos produtos primários elevou-se a uma taxa anual de $14,3 \%$, enquanto a inflação internacional- medida pelo deflator implícito do PIB dos países da Organização para Cooperação e Desenvolvimento Econômico (OCDE) - foi de apenas 6\% a.a., beneficiando, assim, os exportadores dessas mercadorias, como o Brasil, através da melhoria de suas relações de troca (ver Giambiagi (1988)).

\footnotetext{
${ }^{4}$ Ver Bonelli e Malan (1976) e Lago (1990) para uma discussão da política econômica adotada no período 1968-1973.
} 


\subsection{As Reformas do PAEG}

Diversos autores reconhecem a importância das reformas institucionais promovidas pelo PAEG no período 1964-1967 no sentido de criar as bases para o rápido crescimento econômico no período 19681973.5

A questão que se coloca, então, é saber quais são as reformas (e foram muitas as implementadas no governo Castello Branco) a que, efetivamente, se pode creditar o poder de criar instituições pró-mercado ou pró-crescimento econômico.

A visão dos principais formuladores do PAEG serve como ponto de partida. Para Simonsen e Campos (1974, p.119), as reformas implementadas no período 1964-1967 tinham como objetivo remover cinco grandes falhas institucionais, a saber:

“a) a ficção da moeda estável na legislação econômica; b) a desordem tributária; c) a propensão ao déficit orçamentário; d) as lacunas do sistema financeiro; e) os focos de atrito criados pela legislação trabalhista."

Os autores também consideram a maior abertura da economia ao exterior como uma característica fundamental do novo modelo econômico implantado a partir de 1964. De modo geral, esse diagnóstico é compartilhado por outros analistas. Por exemplo, em seu conhecido estudo sobre o PAEG, Resende (1990, p.228) afirma:

"A convicção da necessidade de reformas institucionais acompanhou o PAEG desde seu diagnóstico. Três áreas foram particularmente destacadas, refletindo, acertadamente, a percepção do governo a respeito dos pontos de estrangulamento institucionais da economia: primeiro, a desordem tributária; segundo, as deficiências de um sistema financeiro subdesenvolvido e a inexistência de um mercado de capitais; e, por último, as ineficiências e as restrições ligadas ao comércio exterior."

Sob o ponto de vista dos impactos potenciais no crescimento econômico, as principais reformas associadas ao PAEG foram a reforma fiscal/tributária, a reforma financeira e a abertura da economia ao exterior, que discutimos a seguir.

\subsubsection{Reforma Fiscal/Tributária}

Um dos principais objetivos do PAEG foi promover um forte ajuste fiscal. A meta do ajuste era reduzir os déficits fiscais e, com isso, contribuir para o combate à inflação e criar as condições para uma elevação da poupança do governo, para financiar um aumento dos investimentos públicos e estimular o crescimento econômico.

Com essa finalidade, o governo promoveu uma forte redução de gastos. ${ }^{6}$ Segundo Simonsen e Campos (1974), uma medida fundamental para atingir o objetivo de controle dos gastos públicos foi o dispositivo do Ato Institucional no. 1, posteriormente incorporado à Constituição de 1967, o qual proibiu que o Poder Legislativo elevasse o total de despesas na votação do orçamento da União.

Também foi feita uma ampla reforma tributária. Os objetivos dessa reforma eram elevar a arrecadação do governo e racionalizar o sistema tributário, eliminando impostos em cascata e impostos de pouca funcionalidade econômica, como os impostos do selo. Entre as principais medidas, inclui-se a substituição do imposto estadual sobre vendas, incidente sobre o faturamento das empresas, pelo Imposto sobre Circulação de Mercadorias (ICM), incidente sobre o valor adicionado em cada etapa de comercialização do produto.

\footnotetext{
${ }^{5}$ Ver, por exemplo, Simonsen e Campos (1974), Resende (1990) e Campos (2004).

${ }^{6}$ Ver Resende (1990) e Lago (1990).
} 
Além disso, foram criados mecanismos de reajuste (de acordo com a inflação passada) dos impostos pagos em atraso, o que contribuiu para a elevação da arrecadação real do governo. Como resultado dessas medidas, ocorreu uma significativa elevação da carga tributária da economia brasileira, que passou de 16\% do PIB em 1963 para 21\% em 1967 (ver Hermann (2005)). Em função da redução dos gastos e da elevação da carga tributária, o déficit fiscal federal foi reduzido de 4,2\% do PIB em 1963 para 1,1\% do PIB em 1966 (ver Simonsen e Campos, 1974).

\subsubsection{A Reforma do Sistema Financeiro}

Simonsen e Campos (1974) consideram que a criação de um sistema capaz de fornecer o necessário suporte financeiro ao desenvolvimento econômico do país foi uma das principais realizações econômicas do Governo Castello Branco.

No início da década de 1960, o sistema financeiro brasileiro era particularmente deficiente e inexistia um mercado de capitais. Por exemplo, o controle monetário era bastante precário, já que não havia um Banco Central, sendo suas funções divididas entre o Tesouro Nacional, a Superintendência da Moeda e do Crédito (SUMOC) e o Banco do Brasil.

Além disso, as elevadas taxas de inflação, combinadas com a lei da usura, que proibia juros nominais superiores a $12 \%$ a.a., haviam desestimulado a aplicação de poupanças em títulos de renda fixa, como depósitos a prazo, debêntures e títulos do governo. Em função disso, os déficits fiscais eram financiados quase integralmente por emissões monetárias.

Com a criação do Banco Central (Lei 4.595 de 1964) e a instituição do instrumento da correção monetária, aplicada aos títulos públicos representados pelas Obrigações Reajustáveis do Tesouro Nacional (ORTN), ocorreu um grande aprimoramento institucional da condução da política monetária e do financiamento dos déficits públicos. Enquanto em 1963 apenas 14\% do déficit federal era financiado por títulos governamentais, em 1966 essa parcela elevou-se para 86\% (ver Simonsen e Campos, 1994).

Outra medida foi a criação do Sistema Financeiro da Habitação (SFH), formado pelo recém-criado Banco Nacional da Habitação (BNH), pela Caixa Econômica Federal (CEF), pelas caixas econômicas estaduais, sociedades de crédito imobiliário e associações de poupança e empréstimo (APE). Também foi criado um novo mecanismo de poupança compulsória, o Fundo de Garantia por Tempo de Serviço (FGTS), que se tornou uma importante fonte de recursos para o SFH.

Adicionalmente, foram oferecidos diversos incentivos para a criação de sociedades de crédito e financiamento, voltadas para o crédito direto ao consumidor. Um objetivo importante da reforma financeira foi criar um segmento privado de longo prazo no Brasil, através da criação dos bancos de investimento e estímulos ao mercado de capitais e, em particular, ao mercado de ações.

Segundo Simonsen e Campos (1974), as reformas financeiras promulgadas durante o Governo Castello Branco tiveram seu amplo alcance comprovado a partir de 1968. Em particular, os autores consideram que o crescimento acelerado da construção civil não teria sido possível sem a criação do SFH com o suporte do FGTS. O mesmo se aplica ao excelente desempenho da indústria automobilística e de bens de consumo durável em geral, para o qual foi de grande importância a expansão do crédito ao consumidor.

\subsubsection{A Abertura ao Exterior}

O Governo Castello Branco implementou diversas medidas no sentido de incentivar um maior grau de abertura da economia brasileira ao comércio e ao movimento de capitais com o exterior. $\mathrm{O}$ sistema cambial foi simplificado e unificado, foram modernizadas as agências do setor público ligadas ao comércio exterior e ampliada a integração com o sistema financeiro internacional.

Além disso, a dívida externa foi renegociada e foi aprovada no Congresso a Lei no. 4.390, de julho de 1964, que flexibilizou a Lei de Remessa de Lucros de 1962, revertendo parte dos desincentivos que essa lei havia criado para o ingresso de capitais estrangeiros no país. 
A partir de 1964, também foram introduzidos na legislação brasileira diversos mecanismos de incentivos às exportações, dentre os quais os seguintes:

a) Isenção do imposto sobre as exportações de produtos industrializados (Lei no. 4.502, de novembro de 1964);

b) Isenção do imposto de renda sobre os lucros das exportações (Lei no. 4.663, de junho de 1965);

c) Devolução dos impostos de importação incidentes sobre matérias-primas e componentes importados, que tenham sido utilizados em produtos exportados (Decreto Lei no. 37, de novembro de 1966);

d) Isenção do ICM sobre as exportações de produtos manufaturados (Constituição de 1967).

\section{METODOLOGIA ECONOMÉTRICA E DESCRIÇÃO DAS VARIÁVEIS}

A abordagem empírica que utilizaremos para analisar os determinantes do "milagre" baseia-se em uma versão ampliada do modelo neoclássico de crescimento. O modelo prevê convergência condicional da renda per capita, ou seja, uma vez que se controle para as variáveis que determinam o nível da renda per capita no estado estacionário, países mais pobres tendem a crescer mais rapidamente que países mais ricos. ${ }^{7}$

A idéia básica é que quanto mais distante a economia estiver do estado estacionário, maior é a distância dos níveis de capital físico, humano e eficiência (incluindo o nível tecnológico) dos seus níveis potenciais de longo prazo. Quanto maior essa distância em relação ao potencial de longo prazo, portanto, maior a taxa de crescimento da economia durante o período de transição.

O modelo pode ser representado pela seguinte equação:

$$
g_{i, t}=\beta_{0}+\beta_{1} \log y_{i, t-1}+\beta_{2} Z_{i, t}+\epsilon_{i, t}
$$

onde:

$g_{i, t}$ é a taxa de crescimento da renda per capita do país $i$ no período $t$;

$\log y_{i, t-1}$ é o valor (em log) da renda per capita inicial do país $i$;

$Z_{i, t}$ indica um conjunto de variáveis que influenciam o estado estacionário do país $i$ e $\epsilon_{i, t}$ é o termo de erro da regressão.

O procedimento econométrico consiste em estimar a regressão (1) usando dados de painel para um conjunto de países. Para os objetivos deste artigo, será conveniente decompor a variável $Z_{i, t}$ em dois conjuntos de variáveis. O primeiro conjunto, denotado por $V P_{i, t}$, indica variáveis de política econômica, enquanto o segundo conjunto, $V C_{i, t}$, indica outras variáveis de controle.

Além disso, em função da especificação de painel, introduziremos efeitos fixos, $\mu_{i}$, que capturam efeitos não-observáveis associados à herança histórica, características geográficas, qualidade das instituições e outros determinantes do crescimento que são específicos a cada economia e não variam ao longo do tempo. Também utilizaremos variáveis de efeito-tempo, $\eta_{t}$, que capturam efeitos nãoobserváveis associados a cada período e que são comuns a todas as economias. Fazendo essas modificações em (1), obtemos

$$
g_{i, t}=\gamma_{0}+\gamma_{1} \log y_{i, t-1}+\gamma_{2} V P_{i, t}+\gamma_{3} V C_{i, t}+\mu_{i}+\eta_{t}+\epsilon_{i, t}
$$

\footnotetext{
${ }^{7}$ Neste artigo utilizaremos a expressão "estado estacionário" para denotar a posição de longo prazo das economias, caracterizada por valores constantes do produto e capital por trabalhador efetivo. Nessa situação, as variáveis per capita correspondentes estão em crescimento balanceado, crescendo à taxa de progresso tecnológico.
} 
Nesse artigo, estimaremos (2) usando dados de painel para uma amostra de 62 países durante o período 1962-1997. Utilizaremos inicialmente painéis de seis anos, para os seguintes subperíodos: 1962-1967, 1968-1973, 1974-1979, 1980-1985, 1986-1991 e 1992-1997. ${ }^{8}$

Embora o painel seja estimado para o período 1962-1997, o objetivo da análise é quantificar o crescimento previsto pelo modelo para o período do "milagre" econômico brasileiro (1968-1973), e compará-lo com o crescimento previsto no período anterior (1962-1967).

Nesse sentido, a abordagem é semelhante à empregada em Easterly et alii (1997). Em seu estudo, os autores estimaram um painel de 70 países para o período 1960-1993, com a finalidade de avaliar o efeito das reformas econômicas no crescimento econômico da América Latina entre 1991 e 1993 . O procedimento consiste em estimar (2) usando dados de painel e utilizar os coeficientes estimados e os valores das variáveis no período em análise para prever o crescimento nele ocorrido.

Easterly et alii (1997) identificaram as reformas com o conjunto de variáveis de política econômica, $V P_{i, t}$. Nesse caso, a contribuição das reformas para o crescimento pode ser medida como

$$
\hat{\gamma}_{2} V P_{i, t}
$$

onde $\hat{\gamma}_{2}$ é o valor estimado de $\gamma_{2}$, que mede o impacto marginal das reformas no crescimento da renda per capita.

Os autores estavam particularmente interessados no efeito das reformas na aceleração do crescimento da América Latina entre 1986-1990 e 1991-1993, de modo que calcularam a contribuição das reformas para a variação da taxa de crescimento entre os dois períodos,

$$
g_{i, 91 / 93}-g_{i, 86 / 90}
$$

como

$$
\hat{\gamma}_{2}\left(V P_{i, 91 / 93}-V P_{i, 86 / 90}\right)
$$

Um procedimento análogo pode ser utilizado para calcular as contribuições das demais variáveis que afetam o crescimento econômico, incluindo a contribuição individual de cada variável de política econômica.

Outros artigos têm utilizado abordagens similares para quantificar os determinantes do crescimento na América Latina, como De Gregorio e Lee (1999), Fernández-Arias e Montiel (2001) e Loayza et alii (2005). ${ }^{9}$

A seguir, são descritas as cinco variáveis de política econômica, $V P_{i, t}$, utilizadas no presente artigo.

\subsection{Variáveis de Política Econômica}

a) Com o objetivo de mensurar o grau de estabilidade macroeconômica, utilizaremos a taxa de inflação anual. Os dados de inflação foram obtidos do Global Development Network Growth Database (GDN). ${ }^{10}$

\footnotetext{
${ }^{8}$ Em um segundo momento, serão estimados painéis de dez anos.

${ }^{9}$ Para uma descrição da metodologia de contabilidade do crescimento com o auxílio de regressões e uma aplicação recente para uma amostra grande de países, ver Barro e Sala-I-Martin (2003).

${ }^{10}$ A taxa de inflação obtida a partir do GDN é a variação percentual anual do índice de preços ao consumidor. Para o Brasil, a série de inflação do GDN inicia-se em 1981. Para os anos anteriores, utilizamos a variação percentual anual do IGP como medida da taxa de inflação para o Brasil, obtido de Giambiagi et alii (2005).
} 
b) A variável de política fiscal utilizada será o consumo do governo em relação ao PIB, obtido da Penn-World Table (PWT) 6.1. ${ }^{11}$

c) $\mathrm{O}$ indicador utilizado para medir a participação do sistema financeiro na economia é a razão M2/PIB. Os dados foram obtidos do GDN.

d) Serão utilizadas inicialmente duas variáveis de política para o setor externo. A primeira é o grau de abertura da economia, medido pela razão entre a soma das exportações e importações (volume de comércio) e o PIB. A segunda é o ágio no mercado paralelo. A idéia é que essa variável é uma medida de distorções no mercado de câmbio. A variável de abertura foi obtida da PWT 6.1 e o ágio do mercado paralelo foi obtido do GDN.

Para verificar a robustez dos resultados, utilizaremos também a variável de abertura de Sachs e Warner (1995). Nesse estudo, a classificação do grau de abertura de um país se baseia em uma dummy composta de cinco elementos que caracterizam se um país é fechado: a presença de barreiras nãotarifárias abrangendo $40 \%$ ou mais do comércio; tarifas médias iguais ou acima de $40 \%$; a existência de um ágio no mercado paralelo superior a $20 \%$ nos anos 1970 e 1980; a presença de um sistema socialista; e monopólio estatal nos produtos exportados mais importantes. Um país é considerado aberto se nenhuma das condições acima se aplicarem. Essa variável foi calculada pelos autores para 0 período 1950-1992. Wacziarg e Welch (2003) estenderam o cálculo dessa variável para o período 19921999.

A escolha dessas variáveis foi motivada por duas razões principais. Em primeiro lugar, elas representam aspectos importantes da política econômica adotada durante o período do "milagre", bem como capturam aspectos fundamentais da política de estabilização e das reformas do Governo Castello Branco. Conforme discutido anteriormente, entre as reformas institucionais associadas ao PAEG, as mais importantes sob o ponto de vista do crescimento econômico foram a reforma fiscal/tributária, a reforma financeira e a redução das restrições ao comércio exterior, que estão de certa forma representadas pelas variáveis de política econômica que utilizaremos nesse estudo. Além de estar associada à política de estabilização macroeconômica, a taxa de inflação também captura aspectos importantes das reformas, em particular a reforma fiscal e a mudança na forma de financiamento do déficit público, associada à reforma financeira.

Em segundo lugar, essas variáveis de política econômica têm sido amplamente utilizadas na literatura, incluindo Easterly et alii (1997), De Gregorio e Lee (1999), Fernández-Arias e Montiel (2001), Barro e Sala-I-Martin (2003) e Loayza et alii (2005), entre outros.

\subsection{Outras Variáveis de Controle}

As outras variáveis de controle utilizadas são:

a) Log da renda per capita inicial, para capturar o efeito de convergência associado à distância da economia em relação ao seu estado estacionário, conforme previsto pelo modelo neoclássico. Em períodos relativamente curtos de tempo, como painéis de seis anos, a renda inicial também pode capturar a existência de capacidade ociosa, decorrente de um excesso do produto potencial em relação à produção efetiva. Os dados foram obtidos da PWT 6.1. ${ }^{12}$

\footnotetext{
${ }^{11}$ A PWT 6.1 é uma base de dados que contém informações sobre 23 variáveis para 168 países, de 1950 (para um grupo limitado de países) até 2000. Os dados de produto, investimento e demais estatísticas das Contas Nacionais da PWT são calculados segundo o conceito de paridade de poder de compra (preços internacionais), que corrige os efeitos de diferenças de custo de vida entre países. Para maiores detalhes, ver Heston et alii (2002).

${ }^{12}$ A variável utilizada de renda per capita da PWT 6.1 foi rgdpch.
} 
b) Nível de escolaridade inicial da população com idade igual ou acima de 15 anos. Os dados foram obtidos de Barro e Lee (2000).

c) A taxa de crescimento dos termos de troca, para capturar choques externos específicos a cada economia. Os dados foram obtidos do GDN.

d) Em algumas especificações, utilizaremos uma variável de investimento, medida pela razão investimento/PIB. Os dados foram obtidos da PWT 6.1.

\subsection{Variável Dependente}

A variável dependente utilizada nas regressões será a taxa média de crescimento anual da renda per capita durante o período relevante, construída a partir de dados de renda per capita obtidos da PWT 6.1 .

\section{RESULTADOS}

\subsection{Estatísticas Descritivas}

A Tabela 3 apresenta estatísticas descritivas para a taxa de crescimento da renda per capita e variáveis selecionadas, para os períodos 1962-1967 e 1968-1973, utilizando uma amostra de 62 países. ${ }^{13}$

Tabela 3 - Taxa de Crescimento da Renda per Capita e Variáveis Selecionadas - Médias para o Brasil e para a Amostra - 1962-1967 e 1968-1973 (em \%)

\begin{tabular}{|l|c|c|c|c|c|c|c|}
\hline \multicolumn{1}{|c|}{ Período } & $\begin{array}{c}\text { crescimento } \\
\text { do PIB } \\
\text { per capita }\end{array}$ & $\begin{array}{c}\text { M2/ } \\
\text { PIB }\end{array}$ & $\begin{array}{c}\text { consumo do } \\
\text { governo/ } \\
\text { PIB }\end{array}$ & $\begin{array}{c}\text { ágio } \\
\text { do mercado } \\
\text { paralelo }\end{array}$ & $\begin{array}{c}\text { taxa de } \\
\text { inflação }\end{array}$ & $\begin{array}{c}\text { volume de } \\
\text { comércio/ } / \\
\text { PIB }\end{array}$ & $\begin{array}{c}\text { crescimento } \\
\text { dos termos } \\
\text { de troca }\end{array}$ \\
\hline 1962-1967- Brasil & 2,1 & 15,9 & 31,2 & 31,3 & 53,7 & 7,7 & 4,5 \\
$1968-1973$ - Brasil & 7,9 & 16,8 & 27,4 & 8,9 & 19,1 & 9,5 & 3,2 \\
$1962-1967$ - média amostral & 3,0 & 23,6 & 18,0 & 68,8 & 10,7 & 58,7 & 0,1 \\
1968-1973 - média amostral & 3,4 & 26,8 & 18,5 & 18,4 & 8,9 & 60,7 & 0,5 \\
\hline
\end{tabular}

Fonte: Elaboração própria, com base em dados extraídos do GDN, PWT 6.1 e Barro e Lee (2000).

Nota: A média amostral refere-se à amostra de 62 países utilizada neste artigo.

Como mostra a Tabela 3, enquanto no período 1962 a 1967 a taxa de crescimento média anual da renda per capita no Brasil foi de 2,1\% a.a., o crescimento no período 1968-1973 elevou-se para 7,9\% a.a..

A Tabela 3 também mostra que as variáveis de política econômica referentes ao Brasil tiveram um melhor desempenho no período 1968-1973 em comparação com 1962-1967. No segundo período, o Brasil experimentou uma queda expressiva na taxa de inflação e no ágio do mercado paralelo, além de uma queda no consumo do governo em relação ao PIB. Houve também uma elevação da razão M2/PIB e do grau de abertura da economia, medido pela razão entre o volume de comércio e o PIB.

As médias das variáveis na amostra seguiram a mesma tendência que o Brasil, com exceção da razão entre o consumo do governo e o PIB, que se elevou um pouco na média mundial entre 1962-1967 e 1968-1973.

\footnotetext{
$\overline{{ }^{13} \mathrm{~A} \text { amostra de países é descrita no Apêndice. }}$
} 


\subsection{Resultados Econométricos}

\subsubsection{Painéis de Seis Anos}

No presente artigo, a equação (2) foi estimada usando dados de painel para uma amostra de 62 países durante o período entre 1962 e 1997. Inicialmente, foram utilizados painéis de seis anos, para os seguintes subperíodos: 1962-1967, 1968-1973, 1974-1979, 1980-1985, 1986-1991 e 1992-1997.

As especificações incluem efeitos fixos e de tempo. Também apresentamos resultados para uma especificação que inclui a razão investimento/PIB. Na medida em que controla pela taxa de investimento, essa especificação estima o impacto das variáveis sobre o crescimento econômico através da elevação da taxa de crescimento da produtividade total dos fatores (PTF).

Neste trabalho, apresentaremos resultados econométricos para três estimadores de dados de painel: o estimador de efeito fixo (within-group), o estimador GMM em diferenças de Arellano e Bond (1991) e o estimador GMM de sistema de Blundell e Bond (1998).

O estimador de efeito fixo foi utilizado em um importante estudo de Islam (1995) que, em uma regressão de crescimento com dados de painel, encontrou uma taxa de convergência condicional significativamente maior que a usualmente encontrada em regressões cross-section.

No entanto, o método de estimação de efeito fixo utilizado por Islam (1995) pode gerar um viés nas estimativas do efeito de convergência, em função da correlação entre a variável de renda inicial e o termo de erro. Em função disso, Caselli et alii (1996) introduziram na literatura de regressões de crescimento o estimador GMM em diferenças baseado em Arellano e Bond (1991).

0 procedimento consiste em transformar a equação de crescimento (2) em uma especificação de painel dinâmico - na qual a variável dependente é o log da renda per capita e uma das variáveis explicativas é o log da renda per capita com defasagem de um período - e estimar a versão do modelo em primeiras diferenças. ${ }^{14}$ Para controlar pela endogeneidade da variação do log da renda per capita e de algumas variáveis explicativas, são utilizados como instrumentos valores defasados dos níveis dessas variáveis. Esse procedimento tem sido utilizado em diversos artigos, incluindo Easterly et alii (1997).

No entanto, Blundell e Bond (1998) mostraram que, em amostras pequenas, o estimador GMM em diferenças de Arellano e Bond (1991) pode ser fortemente enviesado na presença de instrumentos fracos, como é o caso, por exemplo, quando as variáveis explicativas são muito persistentes.

Em função disso, Blundell e Bond (1998) propuseram estender o procedimento de Arellano e Bond (1991) através da estimação de um sistema no qual são incluídas as equações em nível, adicionalmente às equações em primeiras diferenças. Para as equações em nível, são utilizados como instrumentos os valores defasados das primeiras diferenças das variáveis. Utilizando o estimador GMM de sistema de Blundell e Bond (1998), Bond et alii (2001) encontraram um grau de convergência condicional bem menor que o encontrado em Islam (1995) e Caselli et alii (1996).

Embora o estimador GMM de sistema de Blundell e Bond (1998) seja provavelmente preferível em razão da discussão anterior, vamos apresentar resultados para os três estimadores a fim de verificar a robustez dos resultados. ${ }^{15}$ A Tabela 4 apresenta os resultados.

As colunas (1) e (2) da Tabela 4 apresentam resultados para o estimador de efeito fixo (EF), sem e com a inclusão da variável de investimento, respectivamente. As colunas (3) e (4) apresentam os resultados para o estimador GMM em diferenças (GMM-DIF), enquanto as colunas (5) e (6) apresentam os resultados para o estimador GMM de sistema (GMM-SIS). ${ }^{16}$

\footnotetext{
${ }^{14} \mathrm{E}$ importante lembrar que a taxa de crescimento pode ser expressa como a diferença do logaritmo da renda per capita em dois instantes do tempo dividida pelo intervalo entre os períodos.

${ }^{15}$ Nas estimações GMM baseadas em Arellano e Bond (1991) e Blundell e Bond (1998), assumimos que as variáveis de escolaridade inicial e crescimento dos termos de troca são exógenas. As demais variáveis explicativas foram consideradas endógenas.

${ }^{16}$ Como mostra a Tabela 4, tanto para o estimador GMM-DIF, como para o GMM-SIS, o teste de Sargan não rejeita a hipótese de que os instrumentos são válidos. Além disso, não é rejeitada a hipótese de que os erros na equação em diferenças não apresentam correlação serial de segunda ordem, o que indica que os erros da equação em nível não apresentam correlação serial
} 
Tabela 4 - Determinantes do Crescimento - Painéis de Seis Anos - 1962-1997

\begin{tabular}{|c|c|c|c|c|c|c|}
\hline \multirow{2}{*}{$\begin{array}{c}\text { Variável dependente } \\
\text { Variáveis explicativas }\end{array}$} & \multicolumn{6}{|c|}{ Taxa de crescimento do produto per capita } \\
\hline & $\begin{array}{l}\text { EF } \\
(1)\end{array}$ & $\begin{array}{l}\text { EF } \\
(2)\end{array}$ & $\begin{array}{c}\text { GMM-DIF } \\
\text { (3) }\end{array}$ & $\begin{array}{c}\text { GMM-DIF } \\
\text { (4) }\end{array}$ & $\begin{array}{c}\text { GMM-SIS } \\
\text { (5) }\end{array}$ & $\begin{array}{c}\text { GMM-SIS } \\
\text { (6) }\end{array}$ \\
\hline Renda per capita inicial & $\begin{array}{c}-3,279^{*} \\
(0,775)\end{array}$ & $\begin{array}{c}-3,498^{*} \\
(0,770)\end{array}$ & $\begin{array}{l}-3,730 * \\
(0,360)\end{array}$ & $\begin{array}{l}-3,831^{*} \\
(0,359)\end{array}$ & $\begin{array}{c}-1,244^{*} \\
(0,062)\end{array}$ & $\begin{array}{l}-1,920^{*} \\
(0,098)\end{array}$ \\
\hline Escolaridade inicial & $\begin{array}{c}-0,032 \\
(0,317)\end{array}$ & $\begin{array}{c}0,052 \\
(0,315)\end{array}$ & $\begin{array}{l}-0,105 \\
(0,362)\end{array}$ & $\begin{array}{l}-0,116 \\
(0,341)\end{array}$ & $\begin{array}{c}0,206 \\
(0,271)\end{array}$ & $\begin{array}{c}0,241 \\
(0,225)\end{array}$ \\
\hline M2/PIB & $\begin{array}{c}1,292^{*} \\
(0,590)\end{array}$ & $\begin{array}{l}1,026^{* *} \\
(0,592)\end{array}$ & $\begin{array}{c}1,763^{*} \\
(0,899)\end{array}$ & $\begin{array}{l}1,194^{* *} \\
(0,711)\end{array}$ & $\begin{array}{l}2,165^{*} \\
(0,739)\end{array}$ & $\begin{array}{c}1,298^{*} \\
(0,582)\end{array}$ \\
\hline Consumo do governo/PIB & $\begin{array}{c}-0,831^{* *} \\
(0,446)\end{array}$ & $\begin{array}{c}-0,608^{* *} \\
(0,391)\end{array}$ & $\begin{array}{c}-0,607 \\
(0,622)\end{array}$ & $\begin{array}{c}0,404 \\
(0,611)\end{array}$ & $\begin{array}{c}-1,247^{* *} \\
(0,742)\end{array}$ & $\begin{array}{l}-0,351 \\
(0,675)\end{array}$ \\
\hline Ágio do mercado paralelo & $\begin{array}{c}-0,269^{* *} \\
(0,157)\end{array}$ & $\begin{array}{l}-0,416^{*} \\
(0,221)\end{array}$ & $\begin{array}{c}0,448 \\
(0,553)\end{array}$ & $\begin{array}{c}0,058 \\
(0,615)\end{array}$ & $\begin{array}{c}-0,131^{* *} \\
(0,079)\end{array}$ & $\begin{array}{c}-0,157^{* *} \\
(0,093)\end{array}$ \\
\hline Taxa de inflação & $\begin{array}{c}-1,541^{*} \\
(0,407)\end{array}$ & $\begin{array}{c}-1,398^{*} \\
(0,405)\end{array}$ & $\begin{array}{l}-1,573^{*} \\
(0,487)\end{array}$ & $\begin{array}{c}-1,241^{* *} \\
(0,663)\end{array}$ & $\begin{array}{l}-0,963^{*} \\
(0,486)\end{array}$ & $\begin{array}{c}-0,804^{* *} \\
(0,478)\end{array}$ \\
\hline Volume de comércio/PIB & $\begin{array}{l}-0,445 \\
(0,605)\end{array}$ & $\begin{array}{l}-0,555 \\
(0,629)\end{array}$ & $\begin{array}{c}-0,801 \\
(1,026)\end{array}$ & $\begin{array}{l}-1,081 \\
(1,030)\end{array}$ & $\begin{array}{l}-0,991 \\
(0,831)\end{array}$ & $\begin{array}{l}-0,990 \\
(0,815)\end{array}$ \\
\hline Crescimento dos termos de troca & $\begin{array}{c}6,886^{*} \\
(3,355)\end{array}$ & $\begin{array}{c}6,578^{*} \\
(3,316)\end{array}$ & $\begin{array}{l}8,173^{* *} \\
(4,271)\end{array}$ & $\begin{array}{l}7,605^{* *} \\
(4,552)\end{array}$ & $\begin{array}{l}9,630^{*} \\
(4,721)\end{array}$ & $\begin{array}{l}7,809^{* *} \\
(4,649)\end{array}$ \\
\hline Investimento/PIB & & $\begin{array}{c}1,499^{*} \\
(0,579)\end{array}$ & & $\begin{array}{c}0,132 \\
(0,451)\end{array}$ & & $\begin{array}{l}2,513^{*} \\
(0,805)\end{array}$ \\
\hline Número de países & 62 & 62 & 62 & 62 & 62 & 62 \\
\hline $\begin{array}{l}\text { Número de observações } \\
\text { Testes de especificação (p valor) }\end{array}$ & 302 & 302 & 238 & 238 & 302 & 302 \\
\hline Teste de Sargan & & & 0,996 & 0,999 & 0,996 & 0,999 \\
\hline Correlação serial de primeira ordem & & & 0,007 & 0,009 & 0,005 & 0,003 \\
\hline Correlação serial de segunda ordem & & & 0,849 & 0,865 & 0,833 & 0,764 \\
\hline
\end{tabular}

Nota: Erro-padrão em parênteses, com correção de Windmeijer (2005) para os estimadores GMM-DIF e GMM-SIS. Renda per capita inicial, M2/PIB, consumo do governo/PIB, volume de comércio/PIB e investimento/PIB são incluídos como ln(variável). Taxa de inflação e ágio do mercado paralelo são incluídos como $\ln (1+$ variável). São utilizados os seguintes estimadores: efeito fixo (EF), GMM em diferenças (GMM-DIF) e GMM de sistema (GMM-SIS).

${ }^{*}$ Estatisticamente significante ao nível de $5 \%$.

** Estatisticamente significante ao nível de $10 \%$.

Os resultados confirmam a existência de convergência condicional, representada pelo coeficiente negativo e estatisticamente significante associado ao log da renda per capita inicial. No entanto, confirmando resultados já encontrados na literatura, o efeito de convergência encontrado é bem menor quando se utiliza o estimador GMM-SIS (ver Bond et alii (2001)).

0 impacto da escolaridade inicial não é estatisticamente significante em nenhuma especificação. ${ }^{17}$ Uma possível explicação é que o período de seis anos (ou mesmo dez anos, como usaremos adiante) é relativamente curto para que o efeito da educação no crescimento seja capturado. Por sua vez, a taxa de crescimento dos termos de troca tem efeito positivo no crescimento do produto per capita e é estatisticamente significante em todas as especificações.

Em relação às variáveis de política econômica, o consumo do governo, o ágio do mercado paralelo e a taxa de inflação têm efeito negativo no crescimento na maioria das especificações, enquanto a razão M2/PIB tem efeito positivo, como seria de se esperar com base nos modelos teóricos. ${ }^{18}$

de primeira ordem. Em conjunto, os resultados desses testes são compatíveis com as hipóteses necessárias para que ambos os estimadores sejam consistentes. Foi utilizada a correção proposta em Windmeijer (2005) para a variância do estimador GMM no procedimento em dois estágios.

${ }^{17}$ Esse resultado é consistente com a literatura empírica. Os estudos que encontram um efeito positivo da educação no crescimento usando dados de painel utilizam, em geral, uma medida de escolaridade que inclui somente o nível de ensino secundário. Ver, por exemplo, Barro e Sala-I-Martin (2003).

${ }^{18}$ Ver Barro e Sala-I-Martin (2003) para uma discussão sobre os sinais esperados dos coeficientes das variáveis de política econômica. 
Dessas variáveis, a razão M2/PIB e a taxa de inflação são estatisticamente significantes em todas as especificações, enquanto o consumo do governo e o ágio do mercado paralelo são significantes para as regressões de efeitos fixos e GMM-SIS, mas não são significantes na regressão GMM-DIF.

O efeito do grau de abertura da economia na taxa de crescimento não é estatisticamente significante em nenhuma especificação. Uma razão pode ser o fato de que essa medida de abertura está associada a variáveis que não necessariamente estão relacionadas a uma política de abertura ao exterior, como o tamanho do país e sua localização geográfica. Em função disso, mais adiante utilizaremos a variável de abertura de Sachs e Warner (1995) para verificar a robustez dos resultados. ${ }^{19}$

A razão investimento/PIB tem um efeito positivo sobre o crescimento em todas as especificações, e esse efeito é estatisticamente significante nas especificações de efeito fixo e GMM-SIS. Quando a variável de investimento é incluída nas regressões, a magnitude do impacto das variáveis de política econômica no crescimento em geral fica menor e menos significante estatisticamente.

Isso indica que parte do efeito das variáveis de política econômica sobre o crescimento econômico ocorre através de uma elevação da taxa de investimento. $O$ fato de que essas variáveis, em geral, são significantes mesmo controlando pela taxa de investimento indica que elas também afetam o crescimento através de uma elevação da PTF.

Em seguida, utilizamos os coeficientes estimados na Tabela 4 para quantificar a contribuição das diversas variáveis para a variação da taxa de crescimento econômico entre 1962-1967 e 1968-1973. Os resultados são apresentados na Tabela 5 .

Tabela 5 - Brasil: Decomposição de Variações nas Taxas de Crescimento da Renda Per Capita entre 1962-1967 e 1968-1973 - Painéis de Seis Anos (em \%)

\begin{tabular}{|c|c|c|c|c|c|c|}
\hline $\begin{array}{l}\text { Contribuições para a variação do } \\
\text { crescimento entre 1962-1967 e 1968-1973 }\end{array}$ & $\begin{array}{l}\mathrm{EF} \\
(1)\end{array}$ & $\begin{array}{l}\text { EF } \\
(2)\end{array}$ & $\begin{array}{l}\text { GMM-DIF } \\
\text { (3) }\end{array}$ & $\begin{array}{c}\text { GMM-DIF } \\
(4)\end{array}$ & $\begin{array}{c}\text { GMM-SIS } \\
\text { (5) }\end{array}$ & $\begin{array}{l}\text { GMM-SIS } \\
(6)\end{array}$ \\
\hline Variação observada & 5,89 & 5,89 & 5,89 & 5,89 & 5,89 & 5,89 \\
\hline Variação prevista & 0,91 & 1,12 & 0,73 & 0,51 & 0,40 & 0,81 \\
\hline$\overline{\text { Renda per capita inicial }}$ & $\overline{-0,40}$ & $\overline{-0,43}$ & $\overline{-0,46}$ & $\overline{-0,47}$ & $\overline{-0,15}$ & $\overline{-0,24}$ \\
\hline Escolaridade inicial & $\overline{-0,01}$ & $\overline{0,01}$ & $\overline{-0,03}$ & $\overline{-0,03}$ & $\overline{0,06}$ & $\overline{0,07}$ \\
\hline Ambiente externo & $\overline{0,71}$ & $\overline{0,78}$ & $\overline{0,91}$ & $\overline{0,91}$ & $\overline{0,16}$ & $\overline{0,32}$ \\
\hline Termos de troca & $-0,09$ & $-0,08$ & $-0,10$ & $-0,10$ & $-0,12$ & $-0,10$ \\
\hline Dummy de período & 0,80 & 0,86 & 1,01 & 1,01 & 0,28 & 0,42 \\
\hline Variáveis de política & 0,61 & 0,45 & 0,32 & 0,08 & 0,33 & 0,13 \\
\hline$\overline{\mathrm{M} 2 / \mathrm{PIB}}$ & $\overline{0,07}$ & $\overline{0,05}$ & $\overline{0,09}$ & $\overline{0,06}$ & $\overline{0,12}$ & $\overline{0,07}$ \\
\hline Consumo do governo/PIB & 0,11 & 0,08 & 0,08 & $-0,05$ & 0,16 & 0,05 \\
\hline Ágio do mercado paralelo & 0,05 & 0,08 & $-0,08$ & $-0,01$ & 0,02 & 0,03 \\
\hline Taxa de inflação & 0,39 & 0,36 & 0,40 & 0,32 & 0,25 & 0,20 \\
\hline Volume de comércio/PIB & $-0,01$ & $-0,12$ & $-0,17$ & $-0,24$ & $-0,22$ & $-0,22$ \\
\hline Investimento/PIB & & 0,31 & & 0,02 & & 0,52 \\
\hline
\end{tabular}

Nota: São utilizados os seguintes estimadores: efeito fixo (EF), GMM em diferenças (GMM-DIF) e GMM de sistema (GMM-SIS).

A Tabela 5 mostra que, enquanto a aceleração da taxa de crescimento média anual da renda per capita entre 1962-1967 e 1968-1973 foi de 5,9 pontos percentuais (p.p.), a aceleração prevista pelo modelo foi bastante pequena, variando entre 0,4 e 1,1 p.p. ao ano, dependendo da especificação econométrica. A contribuição das variáveis de política econômica variou entre 0,1 e 0,6 p.p. ao ano, o que, segundo a maior estimativa, corresponde a pouco mais de $10 \%$ da aceleração do crescimento efetivamente verificada.

\footnotetext{
${ }^{19} \mathrm{O}$ resultado segundo o qual não existe uma relação estatisticamente significante entre abertura e crescimento econômico é consistente com a literatura baseada em regressões de crescimento. Em particular, Rodrik e Rodriguez (2001) mostram que, sob o ponto de vista empírico, não existe uma relação robusta entre abertura e crescimento, embora a maior parte das estimativas seja positiva.
} 
A variável de política econômica que individualmente teve a maior contribuição para a aceleração do crescimento foi a taxa de inflação. É importante observar, no entanto, que essa decomposição da aceleração do crescimento subestima a importância quantitativa das variáveis de cunho mais estrutural. Por exemplo, a contribuição da queda do consumo do governo foi provavelmente maior que a evidenciada na Tabela 5, na medida em que ela também pode ter afetado o crescimento indiretamente através de uma queda na taxa de inflação.

Nesse sentido, embora a Tabela 5 apresente as contribuições individuais de cada variável de política, parece mais recomendável, tanto do ponto de vista econômico, como de significância estatística, enfatizar a contribuição conjunta dessas variáveis.

As variáveis que capturam o ambiente externo também tiveram uma contribuição modesta para a aceleração do crescimento, contribuindo com um valor entre 0,2 e 0,9 p.p. ao ano, o que corresponde a menos de 15\% da variação do crescimento entre 1962-1967 e 1968-1973.

Em resumo, os resultados indicam que o melhor desempenho das variáveis de política econômica e a conjuntura externa favorável associada à grande expansão da economia mundial no período 19681973 contribuíram em conjunto com, no máximo, um quarto da aceleração de crescimento no referido período, comparativamente ao período 1962-1967. As demais variáveis explicam uma pequena parcela da variação do crescimento, de modo que grande parte dessa variação não é explicada pelas variáveis incluídas na especificação econométrica.

Esse resultado não chega a ser surpreendente, se for interpretado à luz da literatura recente. Em particular, Hausmann et alii (2005), analisando mais de 80 episódios de aceleração do crescimento desde a década de 1950 , concluem que as variáveis usualmente empregadas na literatura empírica de crescimento econômico explicam apenas uma pequena parcela das acelerações observadas. Especificamente, embora episódios de aceleração estejam freqüentemente associados a um melhor desempenho das variáveis de política econômica, o impacto quantitativo dessas variáveis é pequeno.

Como mostra a Tabela 5, a contribuição da variável de abertura econômica é negativa em todas as especificações, embora não seja estatisticamente significante, o que contraria a previsão usual de modelos de crescimento. ${ }^{20}$ Para verificar a robustez dos resultados em relação à forma de mensuração do grau de abertura, a Tabela 6 apresenta os resultados da estimação do painel de seis anos quando as variáveis de ágio no mercado paralelo e grau de abertura (razão entre a soma das exportações e importações e o PIB) são substituídas pela variável de abertura de Sachs e Warner (1995).

Os resultados da Tabela 6 são semelhantes aos da Tabela 4. O consumo do governo e a taxa de inflação têm efeito negativo no crescimento na maioria das especificações, enquanto a razão M2/PIB tem efeito positivo. Dessas variáveis, a razão M2/PIB e a taxa de inflação são estatisticamente significantes em todas as especificações, enquanto o consumo do governo só é significante nas regressões de efeito fixo e GMM-SIS sem incluir o investimento.

A razão investimento/PIB tem um efeito positivo e estatisticamente significante no crescimento, com exceção da especificação GMM-DIF. Assim como na Tabela 4, quando a variável de investimento é incluída nas regressões, a magnitude do impacto das variáveis de política econômica em geral fica menor e menos significante estatisticamente. Como as variáveis de política econômica em geral continuam significantes mesmo controlando pela taxa de investimento, isso indica que uma parcela de seu impacto no crescimento verifica-se através de uma elevação da PTF.

Com exceção da especificação GMM-DIF, o efeito da variável de abertura de Sachs-Warner sobre a taxa de crescimento é positivo, mas só é estatisticamente significante na especificação GMM-SIS sem inclusão do investimento.

Em seguida, são utilizados os coeficientes estimados na Tabela 6 para quantificar a contribuição das diversas variáveis para a variação da taxa de crescimento econômico entre 1962-1967 e 1968-1973. Os resultados são apresentados na Tabela 7.

\footnotetext{
${ }^{20}$ Os resultados são semelhantes quando igualamos a zero os coeficientes das variáveis que não são estatisticamente significantes, incluindo o grau de abertura.
} 
Tabela 6 - Determinantes do Crescimento Utilizando a Variável de Abertura de Sachs-Warner - Painéis de Seis Anos -1962-1997

\begin{tabular}{|c|c|c|c|c|c|c|}
\hline Variável dependente & \multicolumn{6}{|c|}{ Taxa de crescimento do produto per capita } \\
\hline Variáveis explicativas & $\begin{array}{l}\text { EF } \\
(1)\end{array}$ & $\begin{array}{l}\text { EF } \\
(2)\end{array}$ & \begin{tabular}{|c|} 
GMM-DIF \\
$(3)$
\end{tabular} & \begin{tabular}{|c|} 
GMM-DIF \\
$(4)$
\end{tabular} & $\begin{array}{c}\text { GMM-SIS } \\
(5)\end{array}$ & $\begin{array}{c}\text { GMM-SIS } \\
\text { (6) }\end{array}$ \\
\hline Renda per capita inicial & $\begin{array}{l}-2,987^{*} \\
(0,776)\end{array}$ & $\begin{array}{c}-3,280^{*} \\
(0,777)\end{array}$ & $\begin{array}{l}-3,429^{*} \\
(0,375)\end{array}$ & $\begin{array}{l}-2,843^{*} \\
(0,271)\end{array}$ & $\begin{array}{l}-1,540^{*} \\
(0,133)\end{array}$ & $\begin{array}{l}-2,529^{*} \\
(0,188)\end{array}$ \\
\hline Escolaridade inicial & $\begin{array}{l}-0,070 \\
(0,319)\end{array}$ & $\begin{array}{l}-0,052 \\
(0,316)\end{array}$ & $\begin{array}{l}-0,348 \\
(0,464)\end{array}$ & $\begin{array}{l}-0,137 \\
(0,457)\end{array}$ & $\begin{array}{c}0,247 \\
(0,419)\end{array}$ & $\begin{array}{c}0,367 \\
(0,349)\end{array}$ \\
\hline M2/PIB & $\begin{array}{l}1,511^{*} \\
(0,565)\end{array}$ & $\begin{array}{l}1,095^{* *} \\
(0,585)\end{array}$ & $\begin{array}{l}1,077^{*} \\
(0,539)\end{array}$ & $\begin{array}{l}1,210^{* *} \\
(0,721)\end{array}$ & $\begin{array}{l}1,582^{* *} \\
(0,869)\end{array}$ & $\begin{array}{l}1,261^{* *} \\
(0,764)\end{array}$ \\
\hline Consumo do governo/PIB & $\begin{array}{c}-0,807^{* *} \\
(0,505)\end{array}$ & $\begin{array}{l}-0,514 \\
(0,708)\end{array}$ & $\begin{array}{c}0,297 \\
(1,291)\end{array}$ & $\begin{array}{c}0,845 \\
(0,657)\end{array}$ & $\begin{array}{c}-1,116^{* *} \\
(0,652)\end{array}$ & $\begin{array}{l}-0,550 \\
(0,570)\end{array}$ \\
\hline Taxa de inflação & $\begin{array}{l}-1,565^{*} \\
(0,382)\end{array}$ & $\begin{array}{c}-1,521^{*} \\
(0,378)\end{array}$ & $\begin{array}{l}-2,163^{*} \\
(0,563)\end{array}$ & $\begin{array}{l}-1,474^{*} \\
(0,667)\end{array}$ & $\begin{array}{c}-0,892^{* *} \\
(0,528)\end{array}$ & $\begin{array}{c}-0,425^{* *} \\
(0,262)\end{array}$ \\
\hline Grau de abertura (Sachs-Warner) & $\begin{array}{c}0,564 \\
(0,552)\end{array}$ & $\begin{array}{c}0,431 \\
(0,549)\end{array}$ & $\begin{array}{c}-0,492 \\
(1,261)\end{array}$ & $\begin{array}{l}-0,510 \\
(1,085)\end{array}$ & $\begin{array}{l}2,040^{*} \\
(0,879)\end{array}$ & $\begin{array}{c}0,256 \\
(0,470)\end{array}$ \\
\hline $\begin{array}{l}\text { Crescimento dos termos de troca } \\
\text { Investimento/PIB }\end{array}$ & $\begin{array}{l}6,464^{*} \\
(3,290)\end{array}$ & $\begin{array}{l}5,800^{* *} \\
(3,275) \\
1,398^{*} \\
(0,572) \\
\end{array}$ & $\begin{array}{l}6,977^{\text {** }} \\
(4,051)\end{array}$ & $\begin{array}{c}5,709^{* *} \\
(3,498) \\
0,401 \\
(0,378) \\
\end{array}$ & $\begin{array}{l}8,312^{* *} \\
(4,441)\end{array}$ & $\begin{array}{l}8,843^{* *} \\
(5,141) \\
3,087^{*} \\
(0,819)\end{array}$ \\
\hline $\begin{array}{l}\text { Número de países } \\
\text { Número de observações } \\
\text { Testes de especificação (p valor) } \\
\text { Teste de Sargan } \\
\text { Correlação serial de primeira ordem } \\
\text { Correlação serial de segunda ordem }\end{array}$ & $\begin{array}{c}62 \\
302\end{array}$ & $\begin{array}{c}62 \\
302\end{array}$ & $\begin{array}{c}62 \\
238 \\
0,898 \\
0,005 \\
0,709\end{array}$ & $\begin{array}{c}62 \\
238 \\
0,999 \\
0,003 \\
0,751\end{array}$ & $\begin{array}{c}62 \\
302 \\
0,996 \\
0,004 \\
0,507\end{array}$ & $\begin{array}{c}62 \\
302 \\
0,999 \\
0,004 \\
0,553\end{array}$ \\
\hline $\begin{array}{l}\text { Nota: Erro-padrão em parênteses, com cc } \\
\text { inicial, M2/PIB, consumo do governo/PIB } \\
\text { ln(1+variável). São utilizados os seguint } \\
\text { SIS). } \\
{ }^{*} \text { Estatisticamente significante ao nível de }\end{array}$ & stimad & 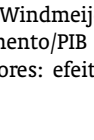 & $\begin{array}{l}\text { (2005) } \\
\text { o inclu } \\
\text { ixo (EF }\end{array}$ & $\begin{array}{l}\text { S esti } \\
\text { omo } 1\end{array}$ & $\begin{array}{l}\text { es GM } \\
\text { vel). }\end{array}$ & $\begin{array}{l}\text { IS. Ren } \\
\text { ção é i } \\
\text { M de si }\end{array}$ \\
\hline
\end{tabular}

Os resultados da Tabela 7 são semelhantes aos da Tabela 5. A Tabela 7 mostra que, enquanto a aceleração da taxa de crescimento média anual da renda per capita entre 1962-1967 e 1968-1973 foi de 5,9 p.p., a aceleração prevista foi bastante pequena, variando entre 0,7 e 1,1 p.p. ao ano, dependendo da especificação econométrica. A contribuição das variáveis de política econômica oscilou entre 0,2 e 0,6 p.p. ao ano, o que, segundo a maior estimativa, corresponde a cerca de $10 \%$ da aceleração do crescimento efetivamente verificada.

A variável de abertura de Sachs-Warner não teve qualquer contribuição para a aceleração do crescimento em 1968-1973, já que, a despeito da maior abertura econômica ao exterior no período, a economia brasileira continuou a ser uma economia fechada segundo a definição dessa variável.

As variáveis que capturam o ambiente externo também tiveram uma contribuição modesta para a aceleração do crescimento, contribuindo com um valor entre 0,3 e 1,0 p.p. ao ano, o que, segundo a maior estimativa, corresponde a menos de $20 \%$ da variação do crescimento entre 1962-1967 e 1968 1973.

Em função da robustez dos resultados à inclusão da variável de abertura de Sachs e Warner, utilizaremos daqui em diante a especificação estimada na Tabela 4 , que usa as variáveis de ágio no mercado paralelo e volume de comércio/PIB como medidas de abertura ao exterior.

Com base nos coeficientes estimados a partir das especificações de efeitos fixos e GMM-SIS da Tabela 4, foram calculadas as taxas de crescimento da renda per capita previstas pelo modelo para o Brasil, que são comparadas na Tabela 8 com as taxas de crescimento que efetivamente se verificaram, para três 
Tabela 7 - Brasil: Decomposição de Variações nas Taxas de Crescimento da Renda Per Capita entre 1962-1967 e 1968-1973 Utilizando a Variável de Abertura de Sachs-Warner - Painéis de Seis Anos (em $\%)$

\begin{tabular}{|c|c|c|c|c|c|c|}
\hline $\begin{array}{l}\text { Contribuições para a variação do } \\
\text { crescimento entre 1962-1967 e 1968-1973 }\end{array}$ & $\begin{array}{l}\mathrm{EF} \\
(1)\end{array}$ & $\begin{array}{l}\text { EF } \\
(2)\end{array}$ & $\begin{array}{l}\text { GMM-DIF } \\
\text { (3) }\end{array}$ & $\begin{array}{c}\text { GMM-DIF } \\
\text { (4) }\end{array}$ & $\begin{array}{l}\text { GMM-SIS } \\
\text { (5) }\end{array}$ & $\begin{array}{l}\text { GMM-SIS } \\
\text { (6) }\end{array}$ \\
\hline Variação observada & 5,89 & 5,89 & 5,89 & 5,89 & 5,89 & 5,89 \\
\hline Variação prevista & 0,75 & 1,05 & 1,09 & 0,83 & 0,67 & 1,03 \\
\hline$\overline{\text { Renda per capita inicial }}$ & $\overline{-0,37}$ & $-\overline{-0,40}$ & $\overline{-0,42}$ & $\overline{-0,35}$ & $-\overline{-0,19}$ & $\overline{-0,31}$ \\
\hline Escolaridade inicial & $\overline{-0,02}$ & $\overline{-0,01}$ & $\overline{-0,10}$ & $\overline{-0,04}$ & $\overline{0,07}$ & $\overline{0,10}$ \\
\hline Ambiente externo & 0,55 & 0,67 & 1,04 & 0,81 & 0,33 & 0,41 \\
\hline Termos de troca & $-0,08$ & $-0,07$ & $-0,09$ & $-0,07$ & $-0,11$ & $-0,11$ \\
\hline Dummy de período & 0,63 & 0,74 & 1,13 & 0,88 & 0,44 & 0,52 \\
\hline Variáveis de política & 0,59 & 0,51 & 0,57 & 0,33 & 0,46 & 0,18 \\
\hline M2/PIB & $\overline{0,08}$ & $\overline{0,06}$ & $\overline{0,06}$ & $\overline{0,06}$ & $\overline{0,08}$ & $\overline{0,07}$ \\
\hline Consumo do governo/PIB & 0,11 & 0,06 & $-0,04$ & $-0,11$ & 0,15 & 0,01 \\
\hline Taxa de inflação & 0,40 & 0,39 & 0,55 & 0,38 & 0,23 & 0,10 \\
\hline Abertura (Sachs-Warner) & 0,00 & 0,00 & 0,00 & 0,00 & 0,00 & 0,00 \\
\hline Investimento/PIB & & 0,28 & & 0,08 & & 0,65 \\
\hline
\end{tabular}

Nota: São utilizados os seguintes estimadores: efeito fixo (EF), GMM em diferenças (GMM-DIF) e GMM de sistema (GMM-SIS).

períodos: 1962-1967, 1968-1973 e 1974-1979. ${ }^{21}$

Tabela 8 - Brasil: Comparação entre Crescimento Previsto e Observado da Renda Per Capita - Painéis de Seis Anos - 1962-1967, 1968-1973, 1974-1979 (em \%)

\begin{tabular}{|c|c|c|c|c|c|}
\hline Período & \multirow{2}{*}{$\begin{array}{c}\text { Taxa de crescimento } \\
\text { observada }\end{array}$} & \multicolumn{4}{|c|}{ Taxa de crescimento prevista } \\
\cline { 3 - 6 } & & (EF-sem inv.) & (EF-com inv.) & (GMM-SIS-sem inv.) & (GMM-SIS-com inv.) \\
\hline $1962-1967$ & 2,05 & 6,07 & 5,61 & 5,70 & 5,44 \\
$1968-1973$ & 7,95 & 6,98 & 6,73 & 6,10 & 6,25 \\
$1974-1979$ & 3,90 & 4,00 & 3,76 & 3,04 & 3,51 \\
\hline
\end{tabular}

Nota: Taxas de crescimento anuais médias da renda per capita observadas e previstas, em que as últimas foram calculadas a partir dos coeficientes estimados nas especificações (1), (2), (5) e (6) da Tabela 4. São utilizados os seguintes estimadores: efeito fixo (EF) e GMM de sistema (GMM-SIS).

Como mostra a Tabela 8, o modelo subestima a taxa de crescimento anual média no período 19681973 em um valor entre 1,0 e 1,9 p.p.. A Tabela 8 também mostra que a previsão de crescimento para 0 período imediatamente anterior, 1962-1967, foi superestimada pelo modelo de forma particularmente acentuada, entre 3,4 e 4,0 p.p. ao ano.

Isso mostra que a incapacidade do modelo de explicar a aceleração associada ao "milagre" decorre da combinação de uma superestimação da taxa de crescimento no período 1962-1967 e de uma subestimação do crescimento no período 1968-1973. Como mostra a Tabela 8, esse resultado é robusto a diferentes especificações econométricas e à inclusão da variável de investimento. ${ }^{22}$

Uma possível explicação para esse resultado seria um erro de especificação no modelo, que não estaria incorporando o efeito de possíveis defasagens das variáveis de política econômica na taxa de crescimento. Para verificar essa possibilidade, estimamos novamente o modelo incorporando defasagens de um período nas variáveis de política econômica. De modo geral, as defasagens não foram

\footnotetext{
${ }^{21}$ As especificações baseadas no estimador GMM-DIF não são apropriadas para prever o nível da taxa de crescimento, já que esse procedimento se baseia na estimação da primeira diferença da equação de interesse.

${ }^{22}$ Os resultados são semelhantes quando a variável de abertura de Sachs-Warner é utilizada em substituição às variáveis de ágio no mercado paralelo e da razão volume de comércio/PIB.
} 
significantes estatisticamente, e a contribuição das variáveis de política econômica para a variação do crescimento no Brasil entre 1962-1967 e 1968-1973 foi semelhante à apresentada nas Tabelas 5 e $7 .{ }^{23}$

A Tabela 8 também mostra que o modelo prevê com certa precisão a taxa de crescimento para o período 1974-1979, cuja previsão varia entre 3,0 e 4,0\% a.a. para as diferentes especificações, enquanto a taxa de crescimento observada foi de 3,9\% a.a..

Esses resultados sugerem a possibilidade de que, pelo menos em parte, a aceleração de crescimento associada ao "milagre" tenha decorrido do efeito defasado das reformas do PAEG (1964-1967). Essa defasagem não teria sido capturada pelo modelo (incluindo ou não defasagens dos efeitos das variáveis de política econômica) por ter sido específica às circunstâncias do Brasil na época. Em particular, deve ser mencionada a necessidade de estabilização macroeconômica diante dos desequilíbrios herdados do Governo João Goulart e o fato de que as mudanças nas variáveis de política no período 1964-1967 decorreram de reformas estruturais e não de mudanças incrementais.

Em seu livro sobre as mudanças ocorridas na economia brasileira a partir de 1964 e seus efeitos nos anos seguintes (Simonsen e Campos, 1974), os principais formuladores do PAEG, Roberto Campos e Mário Henrique Simonsen, analisaram o período 1964-1973 de forma unificada. ${ }^{24}$ A interpretação dos autores é de que, a partir de 1964, o modelo econômico brasileiro teria mudado, no sentido de transformar a economia brasileira em uma economia de mercado aberta ao exterior.

Segundo os autores, os períodos 1964-1967 e 1968-1973 seriam dimensões complementares do mesmo modelo, onde o período 1964-1967 teria sido marcado por mudanças do lado da oferta, enquanto o de 1968-1973 teria se caracterizado pela ativação dos mercados pelo lado da demanda. O período 1964-1967 teria sido caracterizado por um esforço de "restauração", diante da situação de descontrole inflacionário, déficits crônicos no balanço de pagamentos e colapso do investimento, o que implicaria um sacrifício temporário das taxas de crescimento. Para os autores, “...sem esse esforço de restauração, durante o qual o Governo plantou muito para colher pouco, seria virtualmente inconcebível o crescimento acelerado dos últimos anos" (Simonsen e Campos, 1974, p.9). Embora reconheçam o mérito da política econômica do período 1968-1973, Simonsen e Campos (1974, p.10) atribuem parte do "milagre" às políticas implementadas no Governo Castello Branco. Nas suas palavras,

“... parte do chamado 'milagre brasileiro' dos últimos anos deve ser creditada aos sacrifícios estabelecidos durante a administração Castello Branco. Contudo, esse esforço de restauração era condição necessária mas não suficiente para que o país viesse a crescer a taxas aceleradas a partir de 1968. Saber colher é também uma arte, e os responsáveis pela política econômica nos últimos anos vêm revelando extraordinária maestria na técnica de impulsionar o crescimento do produto real, sem agravar tensões inflacionárias e de balanço de pagamentos."

As estimativas reportadas na seção anterior ilustram bem esse ponto. Como mostrou a Tabela 8 , o modelo econométrico superestimou em pelo menos 3,4 p.p. a taxa de crescimento média anual da renda per capita no período 1962-1967. Em função disso e, em menor parcela, devido ao fato de que o modelo subestimou em pelo menos 1,0 p.p. o crescimento médio anual no período 1968 a 1973, a variação prevista pelo modelo entre 1962-1967 e 1968-1973 é inferior à observada em pelo menos 4,4 p.p. ao ano.

Uma possível interpretação desse resultado, com base em Simonsen e Campos (1974), é de que no período 1964-1967 se "plantou muito para colher pouco" e a economia brasileira cresceu bem abaixo de seu novo potencial de longo prazo, que aumentou devido às reformas institucionais. Por outro lado, o crescimento acima do previsto no período 1968-1973 seria decorrente do aproveitamento das oportunidades de crescimento criadas pela política de estabilização e pelas reformas do PAEG. Essa hipótese é testada a seguir.

\footnotetext{
${ }^{23} \mathrm{O}$ resultado de que as defasagens das variáveis de política econômica não são estatisticamente significantes e quantitativamente significativas para o crescimento econômico também foi encontrado em Fernández-Arias e Montiel (2001).

${ }^{24}$ Outros autores, como Hermann (2005), também analisam o período 1964-1973 de forma unificada.
} 


\subsubsection{Painéis de Dez Anos}

Em primeiro lugar, estimamos a equação (2) usando dados de painel de dez anos, para o período 1964-1993, dividido entre os seguintes subperíodos: 1964-1973, 1974-1983 e 1984-1993. Os resultados são apresentados na Tabela 9.

Tabela 9 - Determinantes do Crescimento - Painéis de Dez Anos - 1964-1993

\begin{tabular}{|l|c|c|c|c|c|c|}
\hline \multicolumn{1}{|c|}{ Variável dependente } & \multicolumn{5}{c|}{ Taxa de crescimento do produto per capita } \\
\hline Variáveis explicativas & EF & EF & GMM-DIF & GMM-DIF & GMM-SIS & GMM-SIS \\
& $(1)$ & $(2)$ & $(3)$ & $(4)$ & $(5)$ & $(6)$ \\
\hline Renda per capita inicial & $-4,640^{*}$ & $-4,485^{*}$ & $-3,564^{*}$ & $-4,849^{*}$ & $-0,999^{*}$ & $-1,821^{*}$ \\
& $(0,882)$ & $(0,827)$ & $(0,918)$ & $(2,194)$ & $(0,082)$ & $(0,265)$ \\
Escolaridade inicial & 0,046 & 0,206 & $-0,157$ & $-0,053$ & $-0,021$ & 0,060 \\
& $(0,353)$ & $(0,327)$ & $(0,424)$ & $(0,589)$ & $(0,262)$ & $(0,316)$ \\
M2/PIB & $1,770^{*}$ & $1,647^{*}$ & $2,551^{*}$ & $2,138^{* *}$ & $2,664^{*}$ & $1,840^{* *}$ \\
& $(0,747)$ & $(0,701)$ & $(1,192)$ & $(1,312)$ & $(0,931)$ & $(1,082)$ \\
Consumo do governo/PIB & $-2,508^{*}$ & $-1,894^{*}$ & $-4,756^{*}$ & $-4,285^{*}$ & $-3,334^{*}$ & $-1,101^{* *}$ \\
& $(0,886)$ & $(0,849)$ & $(2,343)$ & $(2,100)$ & $(1,097)$ & $(0,688)$ \\
Ágio do mercado paralelo & $-0,916^{*}$ & $-1,438^{*}$ & 0,788 & $-0,326$ & $-0,336^{* *}$ & $-0,839$ \\
& $(0,467)$ & $(0,462)$ & $(0,916)$ & $(1,482)$ & $(0,207)$ & $(0,599)$ \\
Taxa de inflação & $-0,213^{* *}$ & 0,114 & $-0,638^{* *}$ & $-0,464^{* *}$ & $-0,106^{* *}$ & $-0,205^{* *}$ \\
& $(0,129)$ & $(0,456)$ & $(0,343)$ & $(0,279)$ & $(0,066)$ & $(0,121)$ \\
Volume de comércio/PIB & $-0,562$ & $-1,298^{* *}$ & $-1,651$ & $-1,476$ & $-1,618^{* *}$ & $-0,747$ \\
& $(0,711)$ & $(0,705)$ & $(1,795)$ & $(1,220)$ & $(0,870)$ & $(0,849)$ \\
Crescimento dos termos de troca & $7,110^{* *}$ & $6,464^{* *}$ & $10,684^{* *}$ & $6,985^{* *}$ & $11,702^{*}$ & $9,210^{*}$ \\
& $(3,762)$ & $(3,532)$ & $(6,322)$ & $(4,338)$ & $(5,066)$ & $(4,205)$ \\
Investimento/PIB & & $2,359^{*}$ & & 0,132 & & $2,877^{* *}$ \\
& & $(0,682)$ & & $(1,885)$ & & $(1,663)$ \\
\hline Número de países & 62 & 62 & 62 & 62 & 62 & 62 \\
Número de observações & 152 & 152 & 89 & 89 & 152 & 152 \\
Testes de especificação (p valor) & & & & & & \\
Teste de Sargan & & & 0,829 & 0,407 & 0,700 & 0,493 \\
\hline
\end{tabular}

Nota: Erro-padrão em parênteses, com correção de Windmeijer (2005) para os estimadores GMM-DIF e GMM-SIS. Renda per capita inicial, M2/PIB, consumo do governo/PIB, volume de comércio/PIB e investimento/PIB são incluídos como ln(variável). Taxa de inflação e ágio do mercado paralelo são incluídos como $\ln (1+$ variável). São utilizados os seguintes estimadores: efeito fixo (EF), GMM em diferenças (GMM-DIF) e GMM de sistema (GMM-SIS).

${ }^{*}$ Estatisticamente significante ao nível de 5\%.

** Estatisticamente significante ao nível de 10\%.

Os resultados da Tabela 9 são semelhantes aos da Tabela 4 . O consumo do governo, a taxa de inflação e o ágio no mercado paralelo têm um efeito negativo no crescimento na maioria das especificações, enquanto a razão M2/PIB tem um efeito positivo.

Dessas variáveis, a razão M2/PIB e o consumo do governo são estatisticamente significantes em todas as especificações, enquanto a taxa de inflação é significante em quase todas as especificações. A significância estatística da variável de ágio no mercado paralelo varia dependendo da especificação. Com duas exceções, nas quais tem sinal negativo, a variável de abertura não tem impacto significante no crescimento.

Uma observação importante é que, com exceção da taxa de inflação, a magnitude do impacto das variáveis de política econômica na taxa de crescimento do produto per capita é maior no painel de dez anos (Tabela 9) do que no painel de seis anos (Tabela 4).

Com base nos coeficientes estimados a partir da Tabela 9, foram calculadas as taxas de crescimento da renda per capita previstas pelo modelo para o Brasil, que são comparadas na Tabela $10 \mathrm{com}$ as taxas de crescimento que efetivamente se verificaram, para os três subperíodos: 1964-1973, 1974-1983 e 1984-1993.

Como mostra a Tabela 10, o modelo prevê com um grau substancial de precisão a taxa de crescimento observada no período 1964-1973. Em particular, a taxa de crescimento média prevista pelo modelo para 
Tabela 10 - Brasil: Comparação entre Crescimento Previsto e Observado da Renda Per Capita - Painéis de Dez Anos - 1964-1973, 1974-1983, 1984-1993

\begin{tabular}{|c|c|c|c|c|c|}
\hline Período & $\begin{array}{c}\text { Taxa de crescimento } \\
\text { observada }\end{array}$ & \multicolumn{4}{|c|}{$\begin{array}{c}\text { Taxa de crescimento } \\
\text { prevista }\end{array}$} \\
\cline { 3 - 6 } & & (EF-sem inv.) & (EF-com inv.) & (GMM-SIS-sem inv.) & (GMM-SIS-com inv.) \\
\hline $1964-1973$ & 5,59 & 5,91 & 5,87 & 5,43 & 4,95 \\
$1974-1983$ & 1,74 & 1,49 & 1,58 & 2,94 & 1,48 \\
$1984-1993$ & 1,06 & 0,98 & 0,94 & 2,26 & 0,88 \\
\hline
\end{tabular}

Nota: Taxas de crescimento anuais médias da renda per capita observadas e previstas, em que as últimas foram calculadas a partir dos coeficientes estimados nas especificações (1), (2), (5) e (6) da Tabela 9.

São utilizados os seguintes estimadores: efeito fixo (EF) e GMM de sistema (GMM-SIS).

esse período varia entre 4,9\% e 5,9\% a.a., dependendo da especificação, enquanto a taxa de crescimento observada no período foi de $5,6 \%$ a.a..

O modelo também prevê com certa acurácia as taxas de crescimento para os períodos 1974-1983 e 1984-1993, com exceção das previsões baseadas na especificação GMM-SIS sem inclusão da taxa de investimento, que tendem a superestimar a taxa de crescimento nesses períodos.

Com base nos coeficientes estimados para o painel de dez anos, a Tabela 11 compara as taxas de crescimento da renda per capita previstas e observadas para diversos subperíodos, iniciando com 19641967 e estendendo sucessivamente os subperíodos em um ano até o período 1964-1973.

Tabela 11 - Brasil: Comparação entre Crescimento Previsto e Observado da Renda Per Capita, Diversos Subperíodos (em \%)

\begin{tabular}{|c|c|c|c|c|c|}
\hline Período & $\begin{array}{c}\text { Taxa de crescimento } \\
\text { observada }\end{array}$ & \multicolumn{4}{|c|}{$\begin{array}{c}\text { Taxa de crescimento } \\
\text { prevista }\end{array}$} \\
\cline { 3 - 6 } & & 6,17 & 6,01 & 6,02 & (GMM-SIS-com inv.) \\
\hline $1964-1967$ & 2,05 & 5,99 & 5,81 & 5,69 & 5,03 \\
$1964-1968$ & 3,25 & 5,94 & 5,85 & 5,59 & 4,78 \\
$1964-1969$ & 3,62 & 5,98 & 5,89 & 5,62 & 4,84 \\
$1964-1970$ & 4,08 & 5,91 & 5,83 & 5,48 & 4,93 \\
$1964-1971$ & 4,60 & 5,87 & 5,80 & 5,39 & 4,86 \\
$1964-1972$ & 5,06 & 5,91 & 5,87 & 5,43 & 4,84 \\
$1964-1973$ & 5,59 & (GM-sem inv.) & (EF-com inv. & 4,95 \\
\hline
\end{tabular}

Nota: Taxas de crescimento anuais médias da renda per capita observadas e previstas, em que as últimas foram calculadas a partir dos coeficientes estimados nas especificações (1), (2), (5) e (6) da Tabela 9. São utilizados os seguintes estimadores: efeito fixo (EF) e GMM de sistema (GMM-SIS).

Como mostra a Tabela 11, o modelo superestima a taxa de crescimento anual média no período 1964-1967 em cerca de 3 a 4 p.p., o que é consistente com o resultado obtido anteriormente para o período 1962-1967 (ver Tabela 8). No entanto, à medida em que os anos do "milagre" são incorporados ao período, a taxa de crescimento média observada se eleva e gradualmente se aproxima da taxa de crescimento prevista.

Esses resultados são consistentes com a hipótese de que o período 1964-1967 foi caracterizado por um sacrificio temporário do crescimento econômico, em razão da crise herdada do governo João Goulart e das defasagens associadas aos efeitos das reformas institucionais implantadas no período sobre o crescimento. Por outro lado, a política de estabilização e as reformas do PAEG criaram as condições para que a taxa de crescimento se elevasse no período 1968-1973.

Uma questão bastante debatida na literatura diz respeito à sustentabilidade do "milagre". Com base nos resultados anteriores, o excesso de 2,4 p.p. da taxa de crescimento no período do "milagre" em relação ao crescimento médio do período 1964-1973 decorreu do efeito defasado da política de estabilização e das reformas do PAEG. Em particular, o modelo prevê que, supondo-se que os determinantes do crescimento ficassem inalterados, a taxa de crescimento da renda per capita no Brasil deveria reduzir-se para um valor entre 5 e $6 \%$ a.a. nos anos posteriores ao "milagre". 
No entanto, no período 1974-1983 houve uma queda significativamente maior no crescimento econômico. Com base nas regressões estimadas na Tabela 9, podemos analisar os determinantes da desaceleração do crescimento entre 1964-1973 e 1974-1983. Com essa finalidade, a Tabela 12 utiliza os coeficientes estimados na Tabela 9 para quantificar a contribuição das diversas variáveis para a variação da taxa de crescimento econômico entre 1964-1973 e 1974-1983.

Tabela 12 - Brasil: Decomposição de Variações nas Taxas de Crescimento da Renda Per Capita entre 1964-1973 e 1974-1983 - Painéis de Dez Anos (em \%)

\begin{tabular}{|c|c|c|c|c|c|c|}
\hline \begin{tabular}{|l|} 
Contribuições para a variação do \\
crescimento entre 1964-1973 e 1974-1983
\end{tabular} & $\begin{array}{l}\mathrm{EF} \\
(1)\end{array}$ & $\begin{array}{l}\mathrm{EF} \\
(2)\end{array}$ & $\begin{array}{c}\text { GMM-DIF } \\
\text { (3) }\end{array}$ & $\begin{array}{c}\text { GMM-DIF } \\
\text { (4) }\end{array}$ & $\begin{array}{c}\text { GMM-SIS } \\
\text { (5) }\end{array}$ & $\begin{array}{l}\text { GMM-SIS } \\
\text { (6) }\end{array}$ \\
\hline Variação observada & $-3,85$ & $-3,85$ & $-3,85$ & $-3,85$ & $-3,85$ & $-3,85$ \\
\hline Variação prevista & $-4,41$ & $-4,28$ & $-2,89$ & $\underline{-3,78}$ & $-2,48$ & $-2,28$ \\
\hline Renda per capita inicial & $-2,59$ & $-2,51$ & $-1,99$ & $-2,71$ & $-0,54$ & $-1,02$ \\
\hline Escolaridade inicial & $\underline{0,01}$ & 0,02 & $\overline{-0,02}$ & $\overline{-0,01}$ & $\underline{0,00}$ & 0,01 \\
\hline Ambiente externo & $\overline{-1,29}$ & $\overline{-1,38}$ & $\overline{-1,20}$ & $\overline{-0,82}$ & $\overline{-1,19}$ & $\overline{-1,08}$ \\
\hline Termos de troca & $-0,85$ & $-0,77$ & $-1,28$ & $-0,84$ & $\overline{-1,21}$ & $\overline{-1,11}$ \\
\hline Dummy de período & $-0,44$ & $-0,61$ & 0,08 & 0,02 & 0,02 & 0,03 \\
\hline Variáveis de política & $\underline{-0,53}$ & $\underline{-0,72}$ & $\underline{-0,42}$ & $\underline{-0,48}$ & $-0,75$ & $\underline{-0,82}$ \\
\hline$\overline{\mathrm{M} 2 / \mathrm{PIB}}$ & $\overline{-0,63}$ & $\overline{-0,59}$ & $\overline{-0,92}$ & $\overline{-0,78}$ & $-0,97$ & $-0,66$ \\
\hline Consumo do governo/PIB & 0,44 & 0,33 & 0,84 & 0,76 & 0,59 & 0,19 \\
\hline Ágio do mercado paralelo & $-0,17$ & $-0,26$ & 0,15 & $-0,06$ & $-0,06$ & $-0,16$ \\
\hline Taxa de inflação & $-0,07$ & 0,04 & $-0,20$ & $-0,14$ & $-0,03$ & $-0,06$ \\
\hline Volume de comércio/PIB & $-0,10$ & $-0,22$ & $-0,29$ & $-0,26$ & $-0,28$ & $-0,13$ \\
\hline Investimento/PIB & & $\underline{0,31}$ & & $\underline{0,24}$ & & $\underline{0,63}$ \\
\hline
\end{tabular}

Nota: São utilizados os seguintes estimadores: efeito fixo (EF), GMM em diferenças (GMM-DIF) e GMM de sistema (GMM-SIS).

A Tabela 12 mostra que o modelo explica em grande medida a desaceleração da taxa de crescimento entre os períodos 1964-1973 e 1974-1983. Em particular, enquanto a desaceleração da taxa de crescimento média anual da renda per capita entre 1964-1973 e 1974-1983 foi de 3,9 p.p. ao ano, a desaceleração prevista variou entre 2,3 e 4,4 p.p. ao ano.

Segundo as especificações de efeito fixo e GMM-DIF, o principal determinante da desaceleração entre os dois períodos foi o efeito de convergência associado à renda inicial, cujo efeito correspondeu a uma parcela entre $52 \%$ e $70 \%$ da desaceleração observada. No entanto, conforme discutido anteriormente, alguns autores, como Bond et alii (2001), argumentam que esses estimadores tendem a superestimar a magnitude do efeito de convergência. Os resultados obtidos usando-se o estimador GMM-SIS, que, em princípio, minimiza esse viés, indicam uma importância bem menor do efeito de convergência, variando entre $14 \%$ e $26 \%$ da desaceleração observada.

A importância das variáveis de política econômica para a desaceleração oscila entre $11 \%$ e $21 \%$, dependendo da especificação. O ambiente externo, capturado pelas dummies de tempo e pela taxa de crescimento dos termos de troca, explica algo entre $21 \%$ e $36 \%$ da desaceleração entre 1964-1973 e 1974-1983.

Sumarizando os resultados, se tomarmos como base a especificação GMM-SIS com inclusão do investimento, as contribuições da renda inicial, variáveis de política e ambiente externo foram, respectivamente, de $26 \%, 21 \%$ e $28 \%$, que, em conjunto, explicam cerca de $75 \%$ da desaceleração observada.

\section{CONCLUSÕES}

Com base em uma metodologia de regressões de crescimento com dados de painel, esse artigo determinou a importância quantitativa dos possíveis determinantes do "milagre" econômico brasileiro de 1968-1973. 
Utilizando-se dados de painel de seis anos, os resultados mostram que tanto o ambiente externo como as variáveis de política econômica explicam uma parcela relativamente pequena da aceleração do crescimento econômico brasileiro observada entre 1962-1967 e 1968-1973.

Isso decorre do fato de que o modelo de crescimento estimado com base em painéis de seis anos superestima fortemente o crescimento econômico brasileiro no período anterior ao "milagre" e subestima o crescimento no período do "milagre". Isso sugere a possibilidade de que, pelo menos em parte, a aceleração de crescimento associada ao "milagre" tenha decorrido do efeito defasado das reformas do PAEG.

Para testar essa conjectura, estendemos nossa análise para painéis de dez anos, incluindo o período 1964-1973 entre seus subperíodos. Os resultados mostram que o modelo de regressões de crescimento com dados de painel prevê para o período 1964-1973 uma taxa de crescimento bastante próxima da taxa de crescimento efetivamente verificada.

Esses resultados, combinados com os obtidos para o painel de seis anos, são consistentes com a hipótese de que no período 1964-1967 se "plantou muito para colher pouco", em razão da necessidade de se corrigir os desequilíbrios macroeconômicos e os entraves institucionais herdados do Governo João Goulart. Por outro lado, a política de estabilização e as reformas do PAEG criaram as condições para a aceleração do crescimento em 1968-1973.

Nossos resultados têm pelo menos duas implicações importantes. A primeira é que a combinação dos resultados dos painéis de crescimento de seis e dez anos conduz a uma interpretação do "milagre" econômico brasileiro bastante distinta da que decorre dos estudos de aceleração de crescimento de Rodrik e Subramanian (2004) e Hausmann et alii (2005). Em particular, os resultados indicam que o episódio de aceleração do crescimento associado ao "milagre" decorreu em grande medida do efeito defasado das reformas associadas ao PAEG.

Uma possível razão para a diferença dos resultados deste artigo em relação aos de Hausmann et alii (2005) é o fato de que esses autores utilizaram a variável de abertura de Sachs e Warner (1995) como uma medida de reforma econômica. Como mostrado neste trabalho, a despeito de terem sido implementadas importantes reformas institucionais no período 1964-1967, o valor da variável de abertura de Sachs e Warner para o Brasil não se alterou nesse período. Isso sugere que as variáveis de política econômica utilizadas no presente artigo capturam melhor as reformas que se verificaram no período de interesse.

Outra implicação importante é a evidência de que o efeito das reformas no crescimento econômico pode estar associado a defasagens significativas, especialmente quando as reformas são implementadas em situações de crise econômica, como freqüentemente ocorre. Isso coloca um dilema sob o ponto de vista de economia política, na medida em que os efeitos positivos das reformas não são inteiramente capturados pelos responsáveis pela sua adoção, o que reduz o incentivo para que elas sejam adotadas.

Uma outra questão relevante diz respeito aos determinantes da desaceleração do crescimento econômico no Brasil entre 1964-1973 e 1974-1983. O modelo de regressões de crescimento com dados de painel de dez anos explica em grande medida a desaceleração de crescimento verificada entre esses dois períodos. A renda inicial, as variáveis de política econômica e o ambiente externo contribuíram, cada um, com cerca de $25 \%$ para a redução da taxa de crescimento em 1974-1983.

Portanto, a desaceleração observada se deveu, em um grau de importância aproximadamente igual, a três fatores. O primeiro foi o efeito de convergência associado ao expressivo crescimento econômico do período anterior. Segundo, houve uma piora da qualidade da política econômica. Finalmente, os choques externos também tiveram uma contribuição importante para a queda na taxa de crescimento.

\section{Referências Bibliográficas}

Arellano, M. \& Bond, S. (1991). Some tests of specification for panel data: Monte Carlo evidence and an application to employment equations. Review of Economic Studies, 58(2):277-297. 
Bacha, E. L. \& Bonelli, R. (2004). Accounting for Brazil's growth experience - 1940-2002. Texto para Discussão 1018, IPEA.

Barro, R. J. \& Lee, J. (2000). International data on educational attainment: Updates and implications. Working Paper 7911, National Bureau of Economic Research.

Barro, R. J. \& Sala-I-Martin, X. (2003). Economic Growth. MIT Press, MA, 2nd edition.

Blundell, R. \& Bond, S. (1998). Initial conditions and moment restrictions in dynamic panel data models. Journal of Econometrics, 87(1):115-143.

Bond, S., Hoeffler, A., \& Temple, J. (2001). GMM estimation of empirical growth models. Working Paper. University of Oxford.

Bonelli, R. \& Malan, P. S. (1976). Os limites do possível: Notas sobre balanço de pagamentos e indústria nos anos 70. Pesquisa e Planejamento Econômico, 6(2):353-406.

Campos, R. O. (2004). A lanterna na Popa - Memórias. Topbooks, Rio de Janeiro, 4a edição.

Caselli, F., Esquivel, G., \& Lefort, F. (1996). Reopening the convergence debate: A new look at crosscountry growth empirics. Journal of Economic Growth, 1(3):363-389.

De Gregorio, J. \& Lee, J. (1999). Economic growth in Latin America: Sources and prospects. Centro de Economia Aplicada, Universidade do Chile. Working Paper no. 66.

Easterly, W., Loayza, N., \& Montiel, P. (1997). Has Latin America's post-reform growth been disappointing? Journal of International Economics, 43(3):287-311.

Fernández-Arias, E. \& Montiel, P. (2001). Reform and growth: All pain, no gain? IMF Staff Papers, 48(3):522-546.

Giambiagi, F. (1988). A economia brasileira nos anos do "milagre”: 1968/1973. FEA/UFRJ. Texto Didático, 34.

Giambiagi, F., Villela, A., Barros de Castro, L., \& Hermann, J. (orgs.) (2005). Economia Brasileira Contemporânea. Campus, Rio de Janeiro.

Gomes, V., Pessôa, S., \& Veloso, F. A. (2003). Evolução da produtividade total dos fatores na economia brasileira: Uma análise comparativa. Pesquisa e Planejamento Econômico, 33(3):389-434.

Hausmann, R., Pritchett, L., \& Rodrik, D. (2005). Growth accelerations. Journal of Economic Growth, 10(4):303-329.

Hermann, J. (2005). Reforma, endividamento externo e o 'milagre' econômico (1964/1973). In Giambiagi, F. and Villela, A. and Barros de Castro, L. and Hermann, J. (orgs.), Economia Brasileira Contemporânea. Campus, Rio de Janeiro.

Heston, A., Summers, R., \& Atten, B. (2002). Penn-world table version 6.1. Center for International Comparisons at the University of Pennsylvania.

Islam, N. (1995). Growth empirics: A panel data approach. Quarterly Journal of Economics, 110(4):11271170.

Lago, L. A. (1990). A retomada do crescimento e as distorções do "milagre": 1967-1973. In Abreu, M. (org.), A Ordem Do Progresso. Campus, Rio de Janeiro. 
Loayza, N., Fajnzylber, P., \& Calderón, C. (2005). Economic Growth in Latin America and the Caribbean. The World Bank, Washington, D.C.

Resende, A. L. (1990). Estabilização e reforma: 1964-1967. In Abreu, M. (org.), A Ordem Do Progresso, Rio de Janeiro. Campus.

Rodrik, D. \& Rodriguez, F. (2001). Trade policy and economic growth: A skeptic's guide to the crossnational evidence. In Bernanke, B. and Rogoff, K. (Orgs.), NBER Macroeconomics Annual 2000. MIT Press, Cambridge (MA).

Rodrik, D. \& Subramanian, A. (2004). From 'Hindu growth' to productivity surge: The mystery of the Indian growth transition. National Bureau of Economic Research, Working Paper, no. 10376.

Sachs, J. \& Warner, A. (1995). Economic reform and the process of global integration. Brookings Papers on Economic Activity, 1:1-118.

Simonsen, M. H. \& Campos, R. O. (1974). A Nova Economia Brasileira. José Olympio, Rio de Janeiro.

Wacziarg, R. \& Welch, K. (2003). Trade liberalization and growth: New evidence. National Bureau of Economic Research, Working Paper, no. 10152.

Windmeijer, F. (2005). A finite sample correction for the variance of linear efficient two-step GMM estimators. Journal of Econometrics, 126(1):25-51. 


\section{APÊNDICE}

Tabela 13 - Lista de Países

\begin{tabular}{|c|c|}
\hline África do Sul & Japão \\
Argélia & Lesoto \\
Argentina & Malásia \\
Austrália & Malawi \\
Bolívia & México \\
Brasil & Nepal \\
Camarões & Nicarágua \\
Canadá & Níger \\
Chile & Noruega \\
Cingapura & Nova Zelândia \\
Colômbia & Panamá \\
Congo & Paquistão \\
Coréia do Sul & Paraguai \\
Costa Rica & Peru \\
Dinamarca & Quênia \\
Egito & República Centro-Africana \\
El Salvador & República Dominicana \\
Equador & Ruanda \\
Estados Unidos & Senegal \\
Filipinas & Serra Leoa \\
Gâmbia & Síria \\
Gana & Sri Lanka \\
Grécia & Suíça \\
Guatemala & Tailândia \\
Holanda & Togo \\
Honduras & Trinidad \& Tobago \\
Hong Kong & Uruguai \\
Ilhas Maurício & Venezuela \\
Índia & Zaire \\
Indonésia & Zimbabwe \\
Israel & \\
Jamaica & \\
\hline & \\
\hline
\end{tabular}

